\title{
On the consistency between global and regional methane emissions inferred from SCIAMACHY, TANSO-FTS, IASI and surface measurements
}

\author{
${\text { C. } \text { Cressot }^{1} \text {, F. Chevallier }}^{1}$, P. Bousquet ${ }^{1}$, C. Crevoisier $^{2}$, E. J. Dlugokencky ${ }^{3}$, A. Fortems-Cheiney ${ }^{1}$, C. Frankenberg ${ }^{4}$, \\ R. Parker ${ }^{5}$, I. Pison ${ }^{1}$, R. A. Scheepmaker ${ }^{6}$, S. A. Montzka ${ }^{3}$, P. B. Krummel ${ }^{7}$, L. P. Steele ${ }^{7}$, and R. L. Langenfelds ${ }^{7}$ \\ ${ }^{1}$ Laboratoire des Sciences du Climat et de l'Environnement, UMR8212, 91191 Gif-sur-Yvette, France \\ ${ }^{2}$ Laboratoire de Météorologie Dynamique/CNRS/IPSL, Ecole Polytechnique, Palaiseau, France \\ ${ }^{3}$ Climate Monitoring and Diagnostics Laboratory, NOAA, Boulder, Colorado, USA \\ ${ }^{4}$ Jet Propulsion Laboratory, California Institute of Technology, Pasadena, California, USA \\ ${ }^{5}$ Earth Observation Science, Space Research Centre, University of Leicester, Leicester, UK \\ ${ }^{6}$ SRON Netherlands Institute for Space Research, Utrecht, the Netherlands \\ ${ }^{7}$ Centre for Australian Weather and Climate Research, CSIRO Marine and Atmospheric Research, Aspendale, Victoria, \\ Australia
}

Correspondence to: C. Cressot (cindy.cressot@1sce.ipsl.fr)

Received: 22 February 2013 - Published in Atmos. Chem. Phys. Discuss.: 25 March 2013

Revised: 26 November 2013 - Accepted: 28 November 2013 - Published: 20 January 2014

\begin{abstract}
Satellite retrievals of methane weighted atmospheric columns are assimilated within a Bayesian inversion system to infer the global and regional methane emissions and sinks for the period August 2009 to July 2010. Inversions are independently computed from three different space-borne observing systems and one surface observing system under several hypotheses for prior-flux and observation errors. Posterior methane emissions are compared and evaluated against surface mole fraction observations via a chemistry-transport model. Apart from SCIAMACHY (SCanning Imaging Absorption spectroMeter for Atmospheric CartograpHY), the simulations agree fairly well with the surface mole fractions. The most consistent configurations of this study using TANSO-FTS (Thermal And Near infrared Sensor for carbon Observation - Fourier Transform Spectrometer), IASI (Infrared Atmospheric Sounding Interferometer) or surface measurements induce posterior methane global emissions of, respectively, $565 \pm 21 \mathrm{Tg} \mathrm{yr}^{-1}, 549 \pm 36 \mathrm{Tg} \mathrm{yr}^{-1}$ and $538 \pm 15 \mathrm{Tg} \mathrm{yr}^{-1}$ over the one-year period August 2009July 2010. This consistency between the satellite retrievals (apart from SCIAMACHY) and independent surface measurements is promising for future improvement of $\mathrm{CH}_{4}$ emission estimates by atmospheric inversions.
\end{abstract}

\section{Introduction}

Methane $\left(\mathrm{CH}_{4}\right)$ is the second most important anthropogenic greenhouse gas in terms of radiative forcing after carbon dioxide (Forster, 2007). $\mathrm{CH}_{4}$ sources are of biogenic origin (wetlands, rice cultivation, ruminant animals, termites, landfills and waste), of pyrogenic origin (biomass burning) and of thermogenic origin (production, transport and distribution of fossil fuels, natural geological leakages). The emissions are about $2 / 3$ anthropogenic and $1 / 3$ natural, with large uncertainties for each individual source (20-100\%) (Kirschke et al., 2013). Its loss in the atmosphere, mainly controlled by its chemical reaction with hydroxyl free radical $(\mathrm{OH})$, gives the $\mathrm{CH}_{4}$ molecule a lifetime of about $9 \mathrm{yr}$. Methane concentrations have reached unprecedented values since the beginning of the industrial era $(+150 \%)$ and the explanation for their recent variability is still debated (Bousquet et al., 2011; Rigby et al., 2008). Methane sources and sinks are classically estimated either using bottom-up approaches (process-based modelling and inventories) or top-down approaches (atmospheric inversions). Atmospheric inversions, mostly based so far on surface $\mathrm{CH}_{4}$ observations (Houweling et al., 1999; Bousquet et al., 2006; Bergamaschi et al., 2009, 2010; Pison et al., 2009), have shown to improve bottom-up methane 
emission estimates from global to regional scales. One difficulty with atmospheric inversions is the determination of error statistics attached to atmospheric observations and prior knowledge of emissions and sinks. More or less empirical methods have been set up by various authors to fill the associated covariances matrices (Pison et al., 2009; Bergamaschi et al., 2010; Chen and Prinn, 2006). These approaches generally rely on proxy methods and expert judgement. Since 2003, retrievals of methane mixing ratios from space are available from the SCanning Imaging Absorption spectroMeter for Atmospheric CartograpHY (SCIAMACHY) on board the ENVIronmental SATellite (ENVISAT), largely increasing the number of available constraints for atmospheric inversions, but with a lower individual precision of measurements $(\sim 2 \%)$ as compared to surface observations $(\sim 0.2 \%)$. First inversions using SCIAMACHY retrievals have been produced, with the need for specific and empirical treatment to account for retrieval biases (Meirink et al., 2008).

We study four different observing systems that measure or retrieve $\mathrm{CH}_{4}$ mole fractions $\left(\mathrm{nmol} \mathrm{mol}{ }^{-1}\right.$, abbreviated ppb): SCIAMACHY, the Thermal And Near infrared Sensor for carbon Observation - Fourier Transform Spectrometer (TANSO-FTS) on board the Greenhouse Gas Observing SATellite (GOSAT), the Infrared Atmospheric Sounding Interferometer (IASI) on board the Meteorological Operational Polar satellite (MetOp) and surface air sample sites from various networks (the National Oceanic and Atmospheric Administration (NOAA), the Italian National Agency for New Technology, Energy and the Environment (ENEA), the Japan Meteorological Agency (JMA), the Commonwealth Scientific and Industrial Research Organisation (CSIRO) and the National Institute of Water and Atmospheric Research (NIWA)). These observations do not have the same spatial (horizontal but also vertical) resolution nor the same spatiotemporal sampling, and therefore they are not easy to compare directly. We use the transport model of the Laboratoire de Météorologie Dynamique (LMDz4) coupled with the atmospheric chemistry module Simplified Assimilation Chemical System (SACS) to invert the methane fluxes from each data set on a spatial grid of $3.75^{\circ} \times 2.5^{\circ}$ with a weekly temporal resolution. SACS allows combining methane observations and methyl-chloroform $\left(\mathrm{CH}_{3} \mathrm{CCl}_{3}\right.$, called MCF hereinafter) observations to simultaneously optimize the emissions and oxidation of $\mathrm{CH}_{4}$ (Pison et al., 2009). We compare the posterior methane emissions and losses inferred from the various observing systems at both global and regional scales in order to assess the consistency of their information about methane emissions over the globe. The inversion that assimilates surface measurements is taken here as the reference to evaluate the satellite products.

The theoretical framework used to infer methane emissions and their uncertainties is presented in Sect. 2. The data sets from the various observing systems used in this study are detailed in Sect. 3. Results are presented in Sect. 4 and discussed in Sect. 5, including sensitivity tests introducing a bias correction in the satellite retrievals as a function of the air mass factor and the tuning of the input error statistics.

\section{Method}

\subsection{Inversion system}

Our inversion scheme relies on Bayes' theorem and is based on a variational data assimilation system that has been detailed by Chevallier et al. (2005). The variational formulation of data assimilation provides a powerful technique when the dimension of the observation vector is very large, which is the case with satellites, and when the number of variables to be optimized is large as well, which is the case for grid-point-scale inversions. High-resolution inversions avoid some of the aggregation errors that hit low-resolution inversions (Bocquet et al., 2011; Kaminski et al., 2001). Variational data assimilation involves minimizing a cost function $J$ defined as follows:

$J(x)=\frac{1}{2}\left(x-x^{\mathrm{b}}\right)^{T} \mathbf{B}^{-1}\left(x-x^{\mathrm{b}}\right)+\frac{1}{2}(H(x)-y)^{T} \mathbf{R}^{-1}(H(x)-\boldsymbol{y}) ;$

$\boldsymbol{x}$ is the state vector that contains the variables to be optimized during the inversion process - the time series of weekly grid-point emission fluxes of $\mathrm{CH}_{4}$ and MCF, together with their initial conditions (in the form of 2-D scaling factors on the $\mathrm{CH}_{4}$ and MCF columns) and time series of weekly scaling factors of $\mathrm{OH}$ column concentrations averaged into four bands of latitude $\left(-90^{\circ} /-30^{\circ},-30^{\circ} / 0^{\circ}\right.$, $\left.0^{\circ} / 30^{\circ}, 30^{\circ} / 90^{\circ}\right)$. The vector $x^{\mathrm{b}}$ represents the prior state of $\boldsymbol{x}$, the error statistics of which are defined by the covariance matrix B. Likewise, the vector $\boldsymbol{y}$ contains the observations of $\mathrm{CH}_{4}$ and MCF mole fractions with their associated errors described by the covariance matrix $\mathbf{R}$. Observation errors are defined with respect to the inversion system and therefore combine measurement errors, errors of the chemistrytransport model and representativity errors. The covariance matrix $\mathbf{R}$ is assumed diagonal to simplify calculations, meaning that no correlations between the observation errors are explicitly taken into account. Following Chapnik et al. (2006) and Chevallier (2007), the variances in $\mathbf{R}$ are inflated to account for the missing correlations. $H$ is the non-linear observation operator that projects the state vector $\boldsymbol{x}$ onto the observation space. It contains the LMDz-SACS model presented in Sect. 2.4 and appropriate observation averaging kernels or weighting functions associated with the satellite retrievals.

The iterative minimizing process implies calculating the gradient of the cost function, which is implemented using the adjoint technique. The gradient of $J$ can be written as follows:

$\nabla J(x)=\mathbf{B}^{-1}\left(\boldsymbol{x}-\boldsymbol{x}^{\mathrm{b}}\right)+\mathbf{H}^{T} \mathbf{R}^{-1}(H(\boldsymbol{x})-\boldsymbol{y})$,

where $\mathbf{H}$ is the tangent linear of the observation operator $H$, which is calculated at each iteration. The inversion process is 


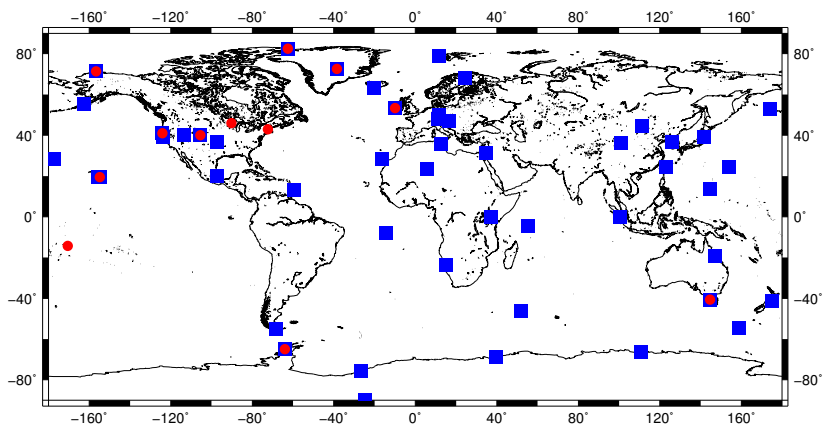

Fig. 1. Surface sites from the NOAA, ENEA, CSIRO, JMA and NIWA networks used in this study with red circles for surface sites observing MCF dry air mole fractions and blue squares for surface sites observing $\mathrm{CH}_{4}$ dry air mole fractions.

iteratively solved with the M1QN3 algorithm developed by Gilbert and Lemaréchal (1989) until the gradient norm gets reduced by more than $99 \%$. The inversion system provides the statistically-optimal solution, given the observations, the prior information and their respective uncertainties (i.e. the maximum of the posterior probability density function), but not directly the uncertainties associated with this solution. In fact, these uncertainties can be estimated by calculating the Hessian matrix but this is practically very costly given the dimension of the state vector. Instead, we use a robust Monte Carlo approach to compute the posterior uncertainties (Chevallier et al., 2007). This method involves performing several inversions with randomly perturbed observations and priors according to their respective error statistics. Because the estimation of the posterior uncertainties seems to become stable from 8 inversions (not shown), an ensemble of ten 19-month inversions (i.e. 190 members) is assumed to be enough to produce an ensemble of solutions well representing the dispersion around the optimal solution $\boldsymbol{x}_{\mathrm{a}}$. It completes the description of the posterior distribution for aggregated values (typically regional and annual). The improvement of methane emissions brought by an inversion is characterized by the uncertainty reduction, defined as one minus the ratio between posterior and prior uncertainties.

In addition to testing default configurations of the inversion system, we perform two sensitivity tests, which are defined as follows.

\subsection{Bias correction}

The first sensitivity test relies on a bias correction for some of the satellite retrievals. In a previous inversion study, Bergamaschi et al. (2009) proposed a bias correction as a function of the latitude and of the month for SCIAMACHY. Here, we parameterize possible biases of SCIAMACHY and TANSOFTS as a function of the air mass factor $A_{\mathrm{F}} . A_{\mathrm{F}}$ is a parameter varying with the latitude as well, but it has the advantage of directly accounting for the geometrical position of the ob- serving satellite and of the Sun.

$A_{\mathrm{F}}=\frac{1}{\cos (\theta)}+\frac{1}{\cos (\xi)}$,

where $\theta$ represents the solar zenith angle and $\xi$ the viewing angle of the satellite. The optimized 4-D $\mathrm{CH}_{4}$ state obtained from the inversion using surface measurements is considered as our reference. We linearly regress the difference between this optimized state and the satellite observations of TANSOFTS and SCIAMACHY against $A_{\mathrm{F}}$ for the 19-month period at once. With 2 parameters only, estimated from the 19 months of the reference inversion with seasonally-varying data coverage, we still consider our reference to be independent from the other inversions for the quantities studied in the following.

\subsection{Tuning of error statistics}

In our second sensitivity test, we use the method of Desroziers et al. (2006) to compute simple diagnostics about the error variances of the observations (diagonal of $\mathbf{R}$ matrix) and of the prior emissions (diagonal of $\mathbf{B}$ matrix) projected into the observation space. In principle, this method is an iterative process in which $\mathbf{B}$ and $\mathbf{R}$ are tuned from the following equations until convergence:

$$
\begin{aligned}
& \left(\mathbf{H B H}^{T}\right)_{i+1}=E\left[\left(H\left(\boldsymbol{x}_{\mathrm{a}}^{\mathrm{i}}\right)-H\left(\boldsymbol{x}_{\mathrm{b}}\right)\right)\left(y-H\left(\boldsymbol{x}_{\mathrm{b}}\right)\right)^{T}\right] \\
& (\mathbf{R})_{i+1}=E\left[\left(y-H\left(\boldsymbol{x}_{\mathrm{a}}^{\mathrm{i}}\right)\right)\left(y-H\left(\boldsymbol{x}_{\mathrm{b}}\right)\right)^{T}\right] \\
& \left(\mathbf{H B H}^{T}\right)_{i+1}+(\mathbf{R})_{i+1}=E\left[\left(y-H\left(\boldsymbol{x}_{\mathrm{b}}\right)\right)\left(y-H\left(\boldsymbol{x}_{\mathrm{b}}\right)\right)^{T}\right]
\end{aligned}
$$

with $i$ the iteration index within this process. Practically, this iterative process is very costly. In fact, Eqs. (4)-(6) require the implementation of the inversion, of which the error statistics are diagnosed, and the implementation of the complete Monte Carlo study associated (i.e. 10 more perturbed inversions see Sect. 2.1). In this study, only one iteration of these diagnostics is implemented for each inversion. Eqs (4)-(6) are applied here to the ensemble defined by all observations at once for the period June 2009-December 2010, i.e. by averaging the diagonals of the matrices described by both sides of the equations. By doing so, both sides are scalar values. These equations allow calculating the values $\operatorname{diag}_{0}, \operatorname{diag}_{\mathrm{b}}$ and diag respectively representing the diagnosed values for the observations, the prior and the full variances (right-hand side of the equations). From our initial inverse set-up, we compute the observation error variances $\left(\operatorname{var}_{0}\right)$, the prior error variances in the observation space $\left(\operatorname{var}_{\mathrm{b}}\right)$ and the sum of the observation error variances and of the prior error variances, called the full variances hereinafter $\left(v a r=\operatorname{var}_{o}+\operatorname{var}_{b}\right)$, that are defined in our system (left-hand side of the equations). $\left(\mathbf{H B H}^{T}\right)_{i+1}$ (i.e. $\operatorname{var}_{\mathrm{b}}$ ) is computed from the spread of a Monte Carlo ensemble simulation, where each ensemble member is drawn from $\mathbf{B}$. The ratio (ratio $=\frac{\mathrm{var}}{\mathrm{diag}}$ ) is an indicator of the goodness of the variances used in our inversions 
and, in the best case, equals one. These diagnostics can be advantageously extended to also tune the error correlations (off diagonal terms of $\mathbf{R}$ and $\mathbf{B}$ ) and not only variances. However, this implies defining retrieval ensembles for each correlation lag, in spite of irregular spatiotemporal sampling; this is not attempted here.

\subsection{Chemistry-transport model: LMDz-SACS}

The inversion scheme includes a chemistry-transport model (CTM) that combines the LMDz4 transport model (Hourdin et al., 2006) in a nudged (towards analysed winds) and offline (transport mass fluxes are precomputed) mode, and the chemistry module SACS implemented by Pison et al. (2009) to estimate the methane emissions that most likely generated the observed mole fractions. The SACS module accounts for the interactions between $\mathrm{CH}_{4}, \mathrm{OH}$ and MCF. Indeed, MCF only reacts with $\mathrm{OH}$, which controls $90 \%$ of the destruction of $\mathrm{CH}_{4}$ in the troposphere. Measurements of MCF mole fractions, the emissions of which are relatively well known, are used as an additional constraint for the $\mathrm{OH}$ modelled mole fractions. $\mathrm{CH}_{4}$ and MCF mole fractions are synergistically optimized during the inversion process to estimate the methane surface sources and the methane atmospheric sink on a spatial grid of $3.75^{\circ} \times 2.5^{\circ}$ and with a weekly temporal resolution.

\section{Prior information and observations}

\subsection{Prior information}

Our system exploits some prior information $\boldsymbol{x}_{\mathrm{b}}$ which combines different standard and recent inventories (Table 1). The anthropogenic emissions of $\mathrm{CH}_{4}$ are drawn from the Emission Database for Global Atmospheric Research EDGAR v4.2 (Olivier and Berdowski, 2001) and biomass burning emissions are from the interannual Global Fire and Emission Database GFED3 (van der Werf et al., 2010), both valid for 2008. No effort is made here to adapt these inventories to the years of the study (2009 and 2010). Other sources are added to these emissions: termites from a study of Sanderson (1996), ocean from Lambert and Schmidt (1993) and wetlands from Kaplan (2002) which have been rescaled by P. Bergamaschi (personal communication, 2009). Soil uptake is based on Ridgwell et al. (1999). The 3-D concentrations of $\mathrm{OH}$ are obtained from a previous simulation of the full atmospheric chemistry model LMDz-INCA (Hauglustaine et al., 2004). MCF emissions are described by the EDGAR v3.2 database and are extrapolated for the years 2009 and 2010 based on a former atmospheric inversion (Bousquet et al., 2005), which has been updated.

Current bottom-up inventories range between $223 \mathrm{Tg} \mathrm{yr}^{-1}$ and $469 \mathrm{Tg} \mathrm{yr}^{-1}$ for the global methane natural sources and between $296 \mathrm{Tg} \mathrm{yr}^{-1}$ and $353 \mathrm{Tg} \mathrm{yr}^{-1}$ for the global methane anthropogenic sources (Kirschke et al., 2013), implying large uncertainties of methane emissions. The standard deviation of the errors of grid-point weekly $\mathrm{CH}_{4}$ prior emissions are defined here as a percentage $(120 \%)$ of the maximum value of the prior emissions between the 8 nearest neighbours in the corresponding month for each grid point (Pison et al., 2009). Errors on $\mathrm{OH}$ scaling factors are set at $\pm 10 \%$ and those on MCF are set at $\pm 1 \%$ of the flux (from now on, the \pm sign is used to represent standard deviations). MCF errors are relatively small because their emissions are considered to be well known, which motivates their use to constrain the $\mathrm{OH}$ concentrations. Errors on the initial conditions are set at $\pm 10 \%$ for MCF concentrations and $\pm 3 \%$ for $\mathrm{CH}_{4}$ concentrations. All error spatial correlations are defined by an efolding length of $500 \mathrm{~km}$ over land and of $1000 \mathrm{~km}$ over sea, without any correlation between land and ocean grid points. Temporal error correlations are all defined by an e-folding length of 2 weeks. Combining variances and correlations, the $\mathrm{CH}_{4}$ prior emissions budget amounts to $554 \pm 51 \mathrm{Tg} \mathrm{yr}^{-1}$, which is consistent with the large range seen among the current bottom-up inventories (Kirschke et al., 2013). This initial $\mathbf{B}$ will be further tuned in a sensitivity test (Sect. 4.3) based on the objective diagnostics described in Sect. 2.3: a scalar factor $\alpha$ is estimated so that the new covariance matrix $\alpha \mathbf{B}$ satisfies Eq. (4).

\subsection{Surface measurements}

Pointwise methane surface measurements are sparsely distributed but provide observations of the dry air mole fractions with high accuracy and precision $(0.2 \%)$. We have selected 49 sites that had regular measurements during the period June 2009-December 2010 (Fig. 1) from the NOAA global cooperative air sampling network (Dlugokencky et al., 1994, 2009), JMA (Matsueda et al., 2004), ENEA (Artuso et al., 2007), CSIRO (Francey et al., 1999) and NIWA (Lowe et al., 1991) networks. The synoptic variability from NOAA's GLOBALVIEW-CH4 (2009) is used as a proxy for transport error, which largely dominates the observation error. Overall, observation standard deviations range from $3.4 \mathrm{ppb}$ (station Casey, Australia) to $58.5 \mathrm{ppb}$ (station Tae-ahn Peninsula, Republic of Korea).

Methyl chloroform (MCF) is a molecule used in the past as an industrial solvent. Its use and emission have been restricted since the Montreal Protocol and its amendments so that its concentration has exponentially decreased in the last decades. Following Montzka et al. (2000, 2011), only flask data from the NOAA network are used in our inversions. Twelve sites have been selected over our study period; they are not homogeneously distributed (Fig. 1). During the inversion process, $\mathrm{OH}$ columns are scaled into 4 latitude bands to fit the $\mathrm{MCF}$ and $\mathrm{CH}_{4}$ observations. In the southern tropical band, only Samoa Observatory (SMO) observes the MCF dry air mole fractions. SMO did not have a regular sampling, with no data between April and July 2010, implying that MCF does not add much constraint on the chemical 
Table 1. Global annual prior methane emissions used in the inversions.

\begin{tabular}{lcl}
\hline Emissions & $\mathrm{Tg} \mathrm{yr}^{-1}$ & Source \\
\hline Anthropogenic emissions & 364 & EDGAR v4.2, Olivier and Berdowski (2001) \\
Biomass burning & 14 & GFED3, van der Werf et al. (2010) \\
Termites & 20 & Sanderson (1996) \\
Ocean & 17 & Lambert and Schmidt (1993) \\
Wetlands & 177 & Kaplan (2002) rescaled by P. Bergamaschi \\
Soil & -38 & (personal communication, 2009) \\
\hline Total & 554 & \\
\hline
\end{tabular}

loss in this band. The MCF monthly variances are averaged over each year from NASA's Advanced Global Atmospheric Gases Experiment (AGAGE) program (Prinn et al., 2005) when available, otherwise from the NOAA. These averages, representing synoptic variability, are used as MCF observation errors. MCF standard deviations range from $0.07 \mathrm{ppt}$ (station Summit, Denmark) to 0.21 ppt (station Harvard Forest Massachusetts, USA).

\subsection{Satellite observations}

SCIAMACHY was operated on board the European satellite ENVISAT between March 2002 and April 2012. It orbited at $800 \mathrm{~km}$ and covered Earth in full every 6 days with a swath of $960 \mathrm{~km}$ and a ground resolution of $30 \mathrm{~km}$ (along track) and $60 \mathrm{~km}$ (across track) at nadir. The instrument observed the solar radiation reflected at the surface and the top of the atmosphere in the short wave infrared (SWIR) domain that allows deducing total columns of methane in cloud-free and sunlight conditions. The ratio of the $\mathrm{CH}_{4}$ and $\mathrm{CO}_{2}$ dry air mole fractions is retrieved together with the corresponding averaging kernels using the Iterative Maximum A Posteriori (IMAPv55) DOAS (differential optical absorption spectroscopy) algorithm initially detailed by Frankenberg et al. (2006). We use this ratio and the 4-D CO 2 analysis from the surface air-sample inversion of Chevallier et al. (2010) to obtain the column-averaged dry air mole fraction of $\mathrm{CH}_{4}\left(\mathrm{XCH}_{4}\right)$. The retrievals have a lower accuracy over the oceans, where the reflection of the solar radiation is very weak and at high latitudes as well. To avoid biases that may be introduced by these data and following Bergamaschi et al. (2009), we limit our study to the observations over land within $50^{\circ}$ from the Equator and for which ground altitudes and model orography differ by less than $250 \mathrm{~m}$. The selected $\mathrm{XCH}_{4}$ data (Fig. 2b) are then averaged (non-weighted by their errors) into grid cells for each time step of the model so that "super-observations" are obtained. Lastly, we remove outliers by suppressing the super-observations whose departure to the prior is larger than three times the standard deviation of all departures. The mean of these averaged observations is about $1747 \mathrm{ppb}$. The uncertainty of the $\mathrm{XCH}_{4}$ re- trievals is around $2 \%$ (Frankenberg et al., 2006). Following Pison et al. (2009) and Spahni et al. (2011), a CTM error of $8 \%$ of the observation values, describing the inability of the model to represent the observations and accounting for correlated errors (see Sect. 2.1), is quadratically added to this retrieval error. In a sensitivity test (Sect. 4.3), a tuning will be computed based on the objective diagnostics described in Sect. 2.3: a scalar factor $\gamma$ is estimated so that the new covariance matrix of the observation errors $\gamma \mathbf{R}$ satisfies Eq. (5).

The Japanese satellite GOSAT was launched in January 2009 and has a polar sun-synchronous orbit at $667 \mathrm{~km}$. It provides a full coverage of Earth every 3 days with a swath of $750 \mathrm{~km}$ and a ground pixel resolution of $10.5 \mathrm{~km}$ at nadir. The TANSO-FTS instrument also observes in the SWIR domain. Version 3.2 of the TANSO-FTS $\mathrm{XCH}_{4}$ proxy retrievals performed at the University of Leicester (Parker et al., 2011) are used with associated averaging kernels and a priori profiles. The $\mathrm{XCH}_{4}$ retrieval algorithm uses an iterative retrieval scheme based on Bayesian optimal estimation. The retrieval accuracy is estimated to be about $0.6 \%$. As for SCIAMACHY, $\mathrm{CO}_{2}$ columns at appropriate time and location from Chevallier et al. (2010) are then used as a proxy for light path to retrieve the averaged mole fractions of methane. A CTM error of $8 \%$ of the observation is quadratically added to this error (see previous paragraph). Given the similarity between SCIAMACHY and TANSO-FTS measurements, we apply the data selection of the previous paragraph (see Fig. 2a), create "super-observations" and remove outliers as well. The assimilated observations have a mean of $1775 \mathrm{ppb}$. Moreover, the covariance matrix for TANSO-FTS R will also be tuned with a scalar $\gamma$ in Sect. 4.3.

The European MetOp-A satellite was launched in October 2006 and has a polar sun-synchronous orbit at an altitude of $817 \mathrm{~km}$. On board MetOp-A, the Infrared Atmospheric Sounding Interferometer (IASI) measures the thermal radiation coming from Earth and the atmosphere in the thermal infrared domain (TIR) with a spectral resolution of $0.5 \mathrm{~cm}^{-1}$ apodized. It provides a full global coverage daily with a swath of $1066 \mathrm{~km}$ and a ground resolution of $12 \mathrm{~km}$ at nadir. The retrieval algorithm is based on a non-linear inference scheme (Crevoisier et al., 2009, 


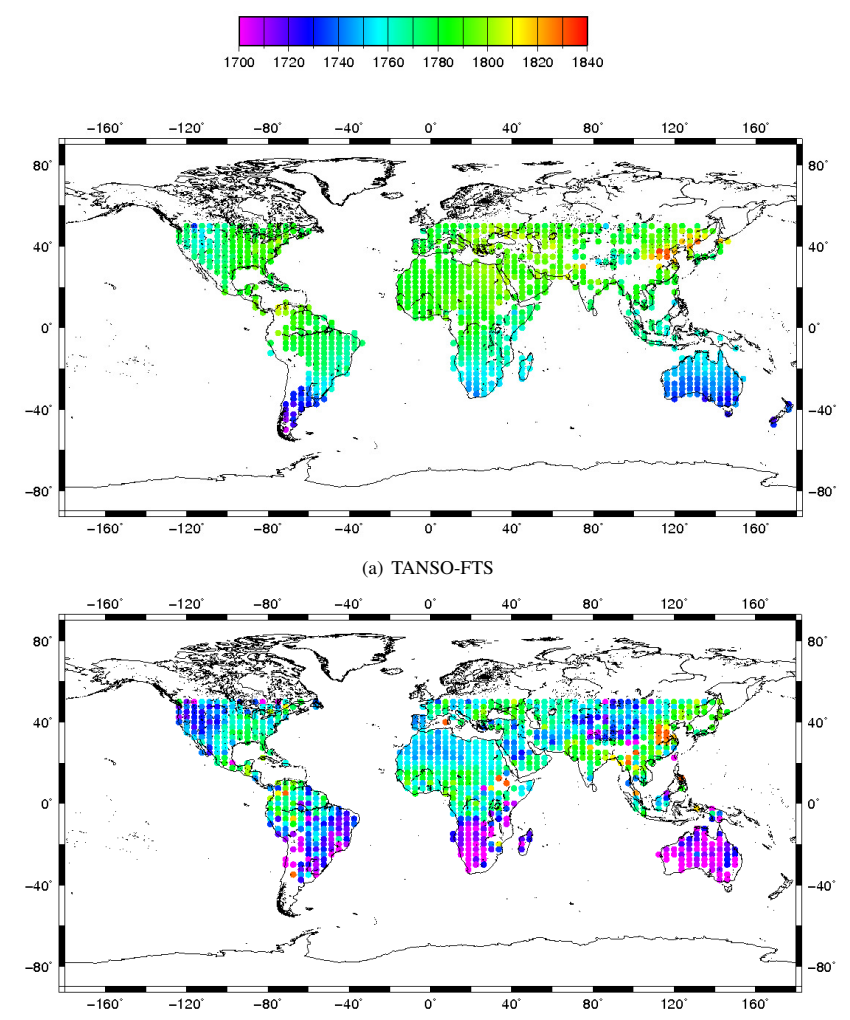

(b) SCIAMACHY

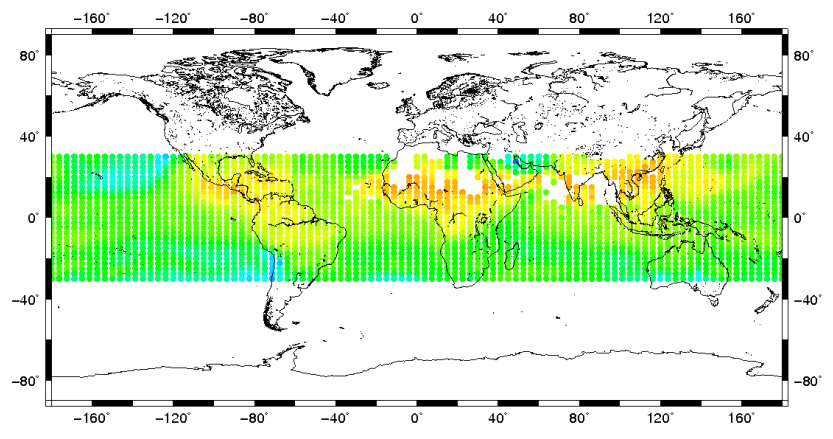

(c) IASI

Fig. 2. Satellite "super-observations" (ppb) used in the inversions for the month of July 2010.

2013). It allows inferring mid-to-upper troposphere columns of methane for the tropical band between $30^{\circ} \mathrm{S}$ and $30^{\circ} \mathrm{N}$, including both land and ocean, twice a day at 09:30 a.m./p.m. local time, with an accuracy of $1.2 \%$. A CTM error of $3 \%$ of the $\mathrm{CH}_{4}$ mid-to-upper troposphere columns is quadratically added to the retrieval error. The lower CTM error compared to TANSO-FTS and SCIAMACHY relates to the lesser vertical extent of the IASI (partial) column retrieval that does not include the boundary layer. IASI retrievals (Fig. 2c) are also averaged into super-observations and outliers are removed as well. This removal suppresses about $10 \%$ of the superobservations which now have a mean of $1788 \mathrm{ppb}$. A tuning of the observation error covariance matrix for IASI is done as for the other instruments in Sect. 4.3.

\section{Results}

A series of grid-point inversions covering the period from June 2009 to December 2010 are computed with the inverse model presented in Sect. 2 and the data sets presented in Sect. 3. To avoid edge effects, we study the methane emissions for the one-year period from August 2009 to July 2010. This time period has been chosen to have all observing systems available. Posterior states given by the inversions are then aggregated at global or regional scales and evaluated at the local scale, i.e. at the surface sites. Each inversion will be called $\mathrm{XX}_{\gamma}^{\alpha}$ with XX a two-letter code specific to each observing system (SC for SCIAMACHY, TA for TANSO-FTS, IA for IASI and SU for surface sites) and $\alpha$ and $\gamma$ the multiplicative factors associated, respectively, with the covariance matrices B (see Sect. 3.1) and $\mathbf{R}$ (see Sect. 3.3).

\subsection{Default configurations}

For this first set of inversions, no tuning of inversions errors is performed. We present and analyse $\mathrm{SU}_{1}^{1}, \mathrm{SC}_{1}^{1}, \mathrm{TA}_{1}^{1}$ and $\mathrm{IA}_{1}^{1}$.

\subsubsection{Global and regional budgets}

Figure 3a presents the methane global annual emissions and losses as inferred by the inversions. When compared to the prior fluxes, the global emission budgets of TANSO-FTS $\left(\mathrm{TA}_{1}^{1}\right)$ and SCIAMACHY $\left(\mathrm{SC}_{1}^{1}\right)$ are respectively increased by $3.9 \%\left(+22 \mathrm{Tg} \mathrm{yr}^{-1}\right)$ and $4.2 \%\left(+24 \mathrm{Tg} \mathrm{yr}^{-1}\right)$ (see Table 3$)$. They are decreased for IASI $\left(\mathrm{IA}_{1}^{1}\right)$ and the surface $\left(\mathrm{SU}_{1}^{1}\right)$ respectively by $2.3 \%\left(-12 \mathrm{Tg} \mathrm{yr}^{-1}\right)$ and $3.6 \%\left(-19 \mathrm{Tg} \mathrm{yr}^{-1}\right)$. Chemical losses are increased by $0.4 \%\left(+2 \mathrm{Tgyr}^{-1}\right)$ for $\mathrm{TA}_{1}^{1}$ only. For the other observing systems, they are decreased by $1.4 \%\left(-8 \mathrm{Tg} \mathrm{yr}^{-1}\right), 0.3 \%\left(-2 \mathrm{Tg} \mathrm{yr}^{-1}\right)$ and $3 \%$ $\left(-17 \mathrm{Tg} \mathrm{yr}^{-1}\right)$ respectively for $\mathrm{SC}_{1}^{1}, \mathrm{IA}_{1}^{1}$ and $\mathrm{SU}_{1}^{1}$. This leads to global annual growth rates of $+39 \mathrm{Tg} \mathrm{yr}^{-1},+51 \mathrm{Tg} \mathrm{yr}^{-1}$, $+9 \mathrm{Tg} \mathrm{yr}^{-1}$ and $+17 \mathrm{Tg} \mathrm{yr}^{-1}$ respectively for $\mathrm{TA}_{1}^{1}, \mathrm{SC}_{1}^{1}, \mathrm{IA}_{1}^{1}$ and $\mathrm{SU}_{1}^{1}$. Uncertainty reductions on global budgets, estimated with a Monte Carlo approach as detailed in Sect. 2.1, are of $41 \%, 51 \%, 56 \%$ and $60 \%$ respectively for $\mathrm{TA}_{1}^{1}$, $\mathrm{SC}_{1}^{1}, \mathrm{IA}_{1}^{1}$ and $\mathrm{SU}_{1}^{1}$ (see Table 2). The global posterior uncertainty is inferred from the uncertainty reduction and the global prior uncertainty of $51 \mathrm{Tg} \mathrm{yr}^{-1}$ and completes the description of posterior global annual estimates of methane. The global emission budgets amount to $576 \pm 30 \mathrm{Tg} \mathrm{yr}^{-1}$, $578 \pm 25 \mathrm{Tg} \mathrm{yr}^{-1}, 542 \pm 22 \mathrm{Tg} \mathrm{yr}^{-1}$ and $535 \pm 20 \mathrm{Tg} \mathrm{yr}^{-1}$ respectively for $\mathrm{TA}_{1}^{1}, \mathrm{SC}_{1}^{1}, \mathrm{IA}_{1}^{1}$ and $\mathrm{SU}_{1}^{1}$. As shown by Fig. 3a, with error bars representing the 1-sigma standard deviations ( $68 \%$ of the posterior distribution), the global emissions and chemical losses of methane inferred from the different 

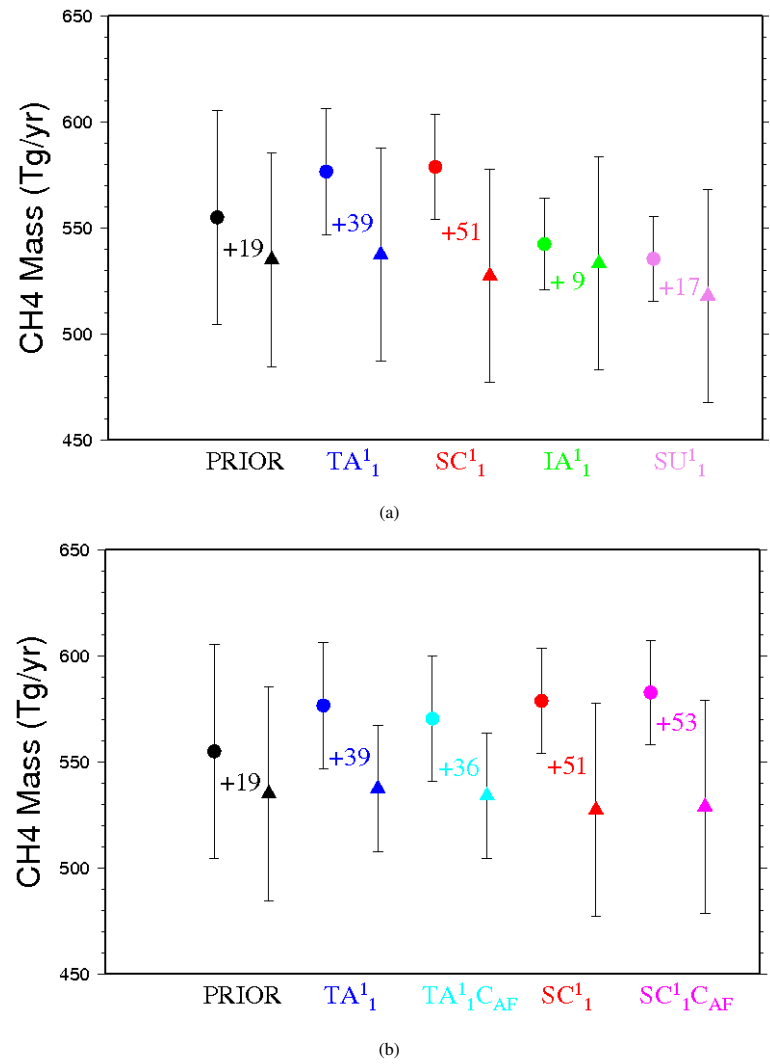

Fig. 3. Global emissions (circles) and losses (triangles) for the configurations $\mathrm{TA}_{1}^{1}$ (blue), $S C_{1}^{1}$ (red), $\mathrm{IA}_{1}^{1}$ (green) and $\mathrm{SU}_{1}^{1}$ (violet) (a) and for $\mathrm{TA}_{1}^{1}$ (dark blue), $\mathrm{SC}_{1}^{1}$ (red) and bias-corrected configurations $\mathrm{TA}_{1}^{1} C_{\mathrm{AF}}$ (light blue) and $\mathrm{SC}_{1}^{1} C_{\mathrm{AF}}$ (magenta) (b). Numbers describe the global growth rates in $\mathrm{Tg}^{-1}$ inferred by the inversions. Error bars represent the posterior uncertainties estimated with the Monte Carlo study (see Section 2.1).

observing systems are statistically consistent with each other, in the sense that they agree within at least two sigmas.

The methane emissions are then aggregated over large continental regions (shown in Fig. 4a and adapted from Gurney et al., 2002). As shown by Fig. 4b, the three satellites show a very good agreement for 8 regions: North American Boreal, USA, South American Temperate, Southern Africa, West Europe, Eurasian Boreal, Middle East and Australia. In some of them (USA, South American Temperate, Southern Africa, West Europe, Eurasian Boreal and Middle East), this agreement combined with significant uncertainty reductions reflects a good improvement of our knowledge of methane emissions. For some other regions (North American Boreal and Australia), the inversion process infers marginal increments and very weak uncertainty reductions for the three satellites, meaning that we do not really improve our knowledge of methane emissions for these regions. Large differences are found between satellite- and surface-based inversions for regions USA, South American Temperate and South

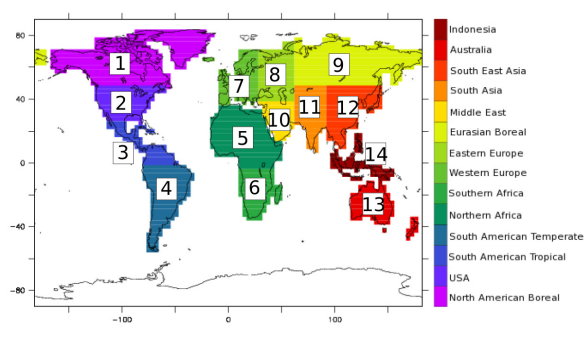

(a)
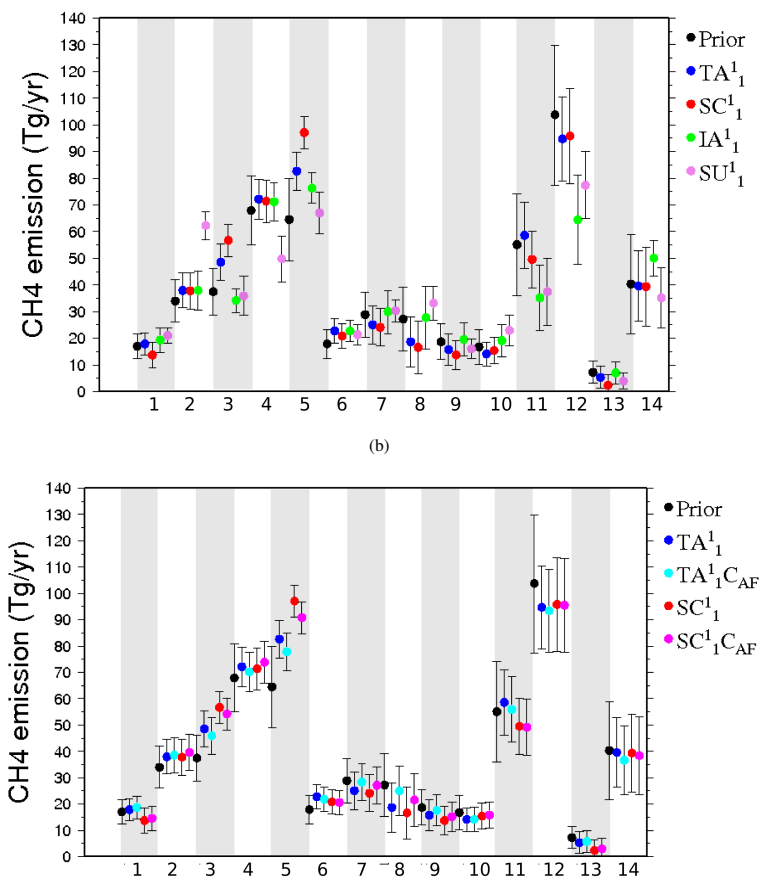

Fig. 4. (a) Sub-continental regions inspired from Gurney et al. (2002). Regional methane emissions for default configurations $\mathrm{TA}_{1}^{1}$ (blue), $\mathrm{SC}_{1}^{1}$ (red), $\mathrm{IA}_{1}^{1}$ (green) and $\mathrm{SU}_{1}^{1}$ (violet) (b) and for configurations $\mathrm{TA}_{1}^{1}$ (dark blue), $\mathrm{SC}_{1}^{1}$ (red) and bias-corrected configurations $\mathrm{TA}_{1}^{1} C_{\mathrm{AF}}$ (light blue) and $\mathrm{SC}_{1}^{1} C_{\mathrm{AF}}$ (magenta) (c). Error bars represent the posterior uncertainties estimated with the Monte Carlo study (see Section 2.1)

East Asia. The surface-based inversion does not agree with the satellite ones, especially in the Tropics where there are few surface data. It seems that the increments found in region USA by the surface-based inversion are highly overestimated. Large differences between IASI and the other observing systems are found in regions South East Asia and Indonesia. The IASI-based inversion achieves high uncertainty reductions for these regions (64\% in Indonesia and 51\% in South East Asia). However, the uncertainty reduction computation only accounts for random errors but biases in the transport model for this area may degrade the actual performance. Therefore, the differences are more likely due to a misattribution of the emissions in these regions because of a 
Table 2. Uncertainty reduction (\%) on methane emissions for the default configurations.

\begin{tabular}{lcccc}
\hline Regions & $\mathrm{TA}_{1}^{1}$ & $\mathrm{SC}_{1}^{1}$ & $\mathrm{IA}_{1}^{1}$ & $\mathrm{SU}_{1}^{1}$ \\
\hline North American Boreal & 07 & 00 & 00 & 41 \\
USA & 18 & 15 & 10 & 35 \\
South American Tropical & 21 & 31 & 48 & 16 \\
South American Temperate & 41 & 37 & 43 & 33 \\
Northern Africa & 53 & 61 & 63 & 49 \\
Southern Africa & 13 & 12 & 24 & 29 \\
West Europe & 15 & 16 & 04 & 51 \\
East Europe & 21 & 15 & 00 & 46 \\
Eurasian Boreal & 11 & 17 & 06 & 45 \\
Middle East & 30 & 24 & 07 & 13 \\
South Asia & 35 & 44 & 35 & 33 \\
South East Asia & 39 & 32 & 36 & 51 \\
Australia & 01 & 00 & 02 & 26 \\
Indonesia & 29 & 20 & 64 & 38 \\
Global & 41 & 51 & 56 & 60 \\
\hline
\end{tabular}

larger footprint of the IASI free tropospheric column combined with a lack of retrievals during the monsoon period.

\subsubsection{Initial conditions}

2-D scaling factors adjust the initial conditions of $\mathrm{CH}_{4}$ and MCF on 1 June 2009 at 00:00 UTC (see Sect. 3.1) and therefore influence the mass budget of the inversion. After the inversions $\mathrm{SC}_{1}^{1}, \mathrm{TA}_{1}^{1}, \mathrm{IA}_{1}^{1}$ and $\mathrm{SU}_{1}^{1}$, the initial $\mathrm{CH}_{4}$ columns show increments of about $1.1 \pm 0.6 \%, 0.7 \pm 0.6 \%, 0.8 \pm 1.0 \%$ and $0.8 \pm 0.7 \%$ respectively. The spatial distribution of these columns is very different between SCIAMACHY and the other observing systems. Figure $5 \mathrm{~b}$ shows a decrease of the amplitude of the columns in the two hemispheres that can reach $3 \%$ for SCIAMACHY, with a slight increase in the Tropics (less than 1\%). However, for TANSO-FTS, IASI and the surface sites, Fig. 5a, c, 6a show an increase especially located in the Southern Hemisphere that can reach $4 \%$ for IASI, $3 \%$ for TANSO-FTS and $2 \%$ for the surface.

\subsubsection{Fit to surface measurements}

The fit to the surface data is summarized by the absolute mean of the biases (called mean bias hereinafter) and the root mean squares of the bias (called rms hereinafter) (last 2 columns of Table 3) between the posterior states obtained by using the different data sets, respectively $\mathrm{TA}_{1}^{1}$, $\mathrm{SC}_{1}^{1}, \mathrm{IA}_{1}^{1}$ and $\mathrm{SU}_{1}^{1}$, and their equivalent seen at each surface site (see Figs. 7a-c and 8a respectively). The mean bias obtained by $\mathrm{TA}_{1}^{1}$ is $4.1 \mathrm{ppb}$, which is well bellow the $\mathrm{SC}_{1}^{1}$ one (39.1 ppb) and the $\mathrm{IA}_{1}^{1}$ one (13.0 ppb), and close to the $\mathrm{SU}_{1}^{1}$ one $(0.8 \mathrm{ppb})$. The rms obtained by $\mathrm{TA}_{1}^{1}$ is $15.4 \mathrm{ppb}$, the one by $\mathrm{SC}_{1}^{1}$ is $40.5 \mathrm{ppb}$, the one by $\mathrm{IA}_{1}^{1}$ is $20.0 \mathrm{ppb}$ and the one by $\mathrm{SU}_{1}^{1}$ is $5.5 \mathrm{ppb}$. Note that for $\mathrm{SU}_{1}^{1}$, surface observa-

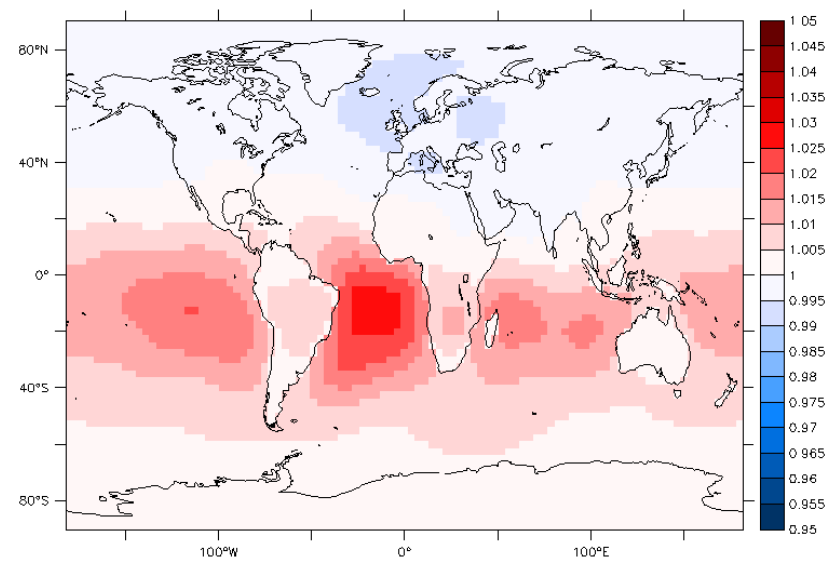

(a) $T A_{1}^{1}$

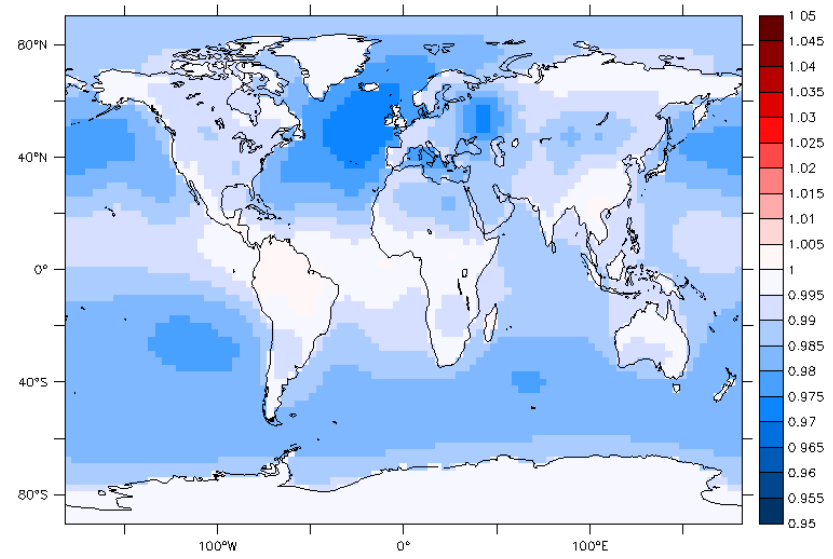

(b) $S C_{1}^{1}$

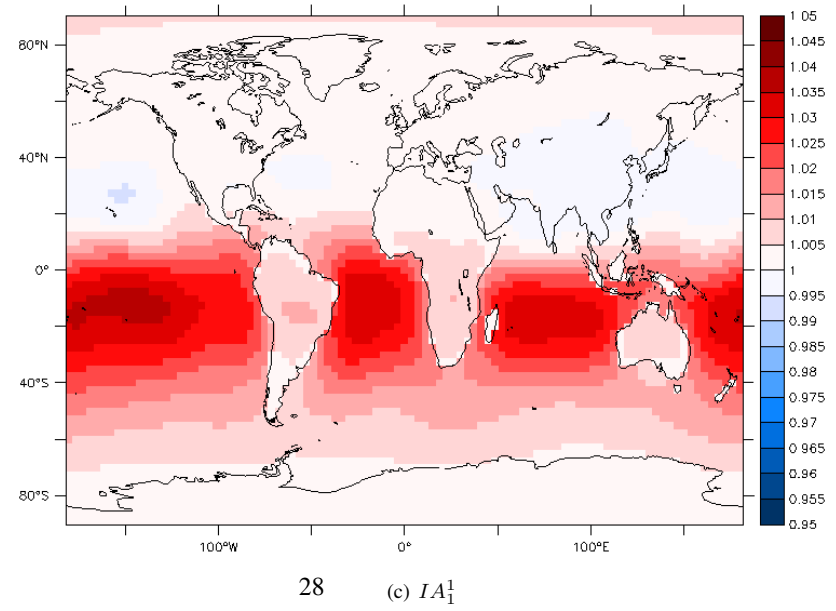

Fig. 5. Increments of the initial conditions of methane for the various inversions expressed as a fraction of the prior.

tions are assimilated by the inverse system, therefore explaining low rms and mean-bias values. Only the SCIAMACHYbased inversion does not result in improved agreement with surface measurements when compared to the prior mean bias (24.3 ppb) and rms (28.1 ppb). 


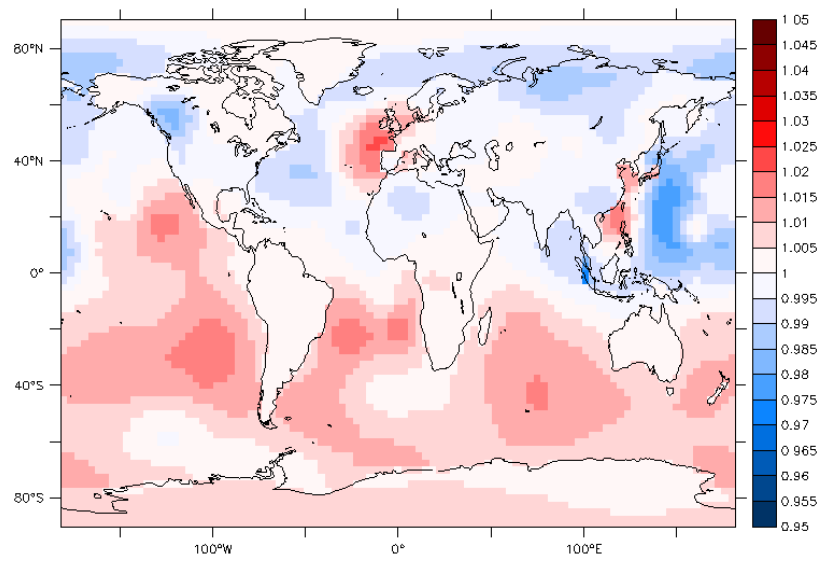

(a) $S U_{1}^{1}$

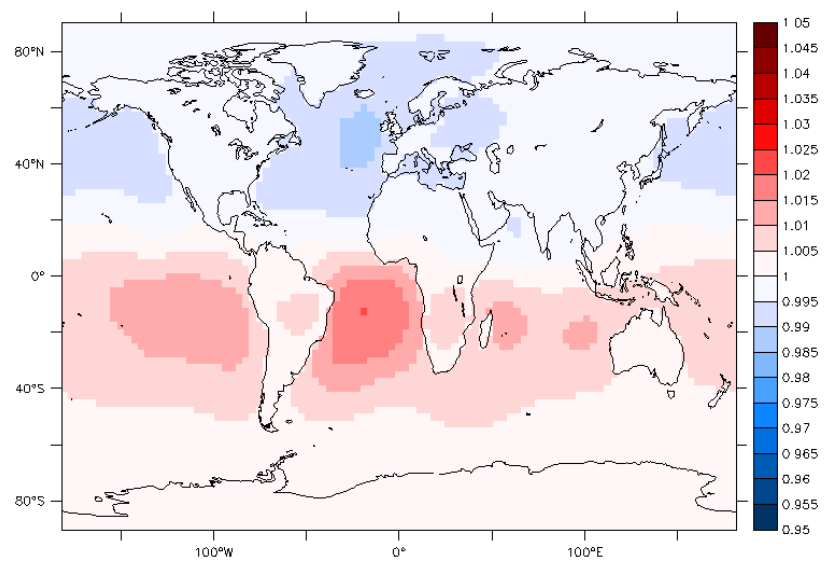

(b) $T A_{1}^{1} C_{A F}$

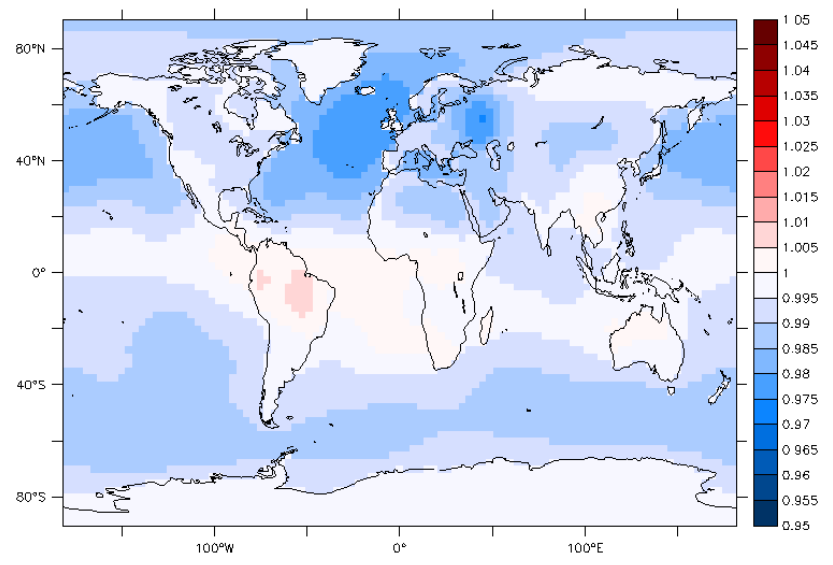

(c) $S C_{1}^{1} C_{A F}$

Fig. 6. Increments of the initial conditions of methane for the various inversions expressed as a fraction of the prior.

\subsection{Bias correction}

A bias correction as a function of the air mass factor $A_{\mathrm{F}}$ (see Sect. 2.2) is applied to TANSO-FTS and SCIAMACHY retrievals, as presented in Sect. 3.3. $\mathrm{SC}_{1}^{1} \mathrm{C}_{\mathrm{AF}}$ and $\mathrm{TA}_{1}^{1} \mathrm{C}_{\mathrm{AF}}$ represent the inversions using bias-corrected satellite retrievals

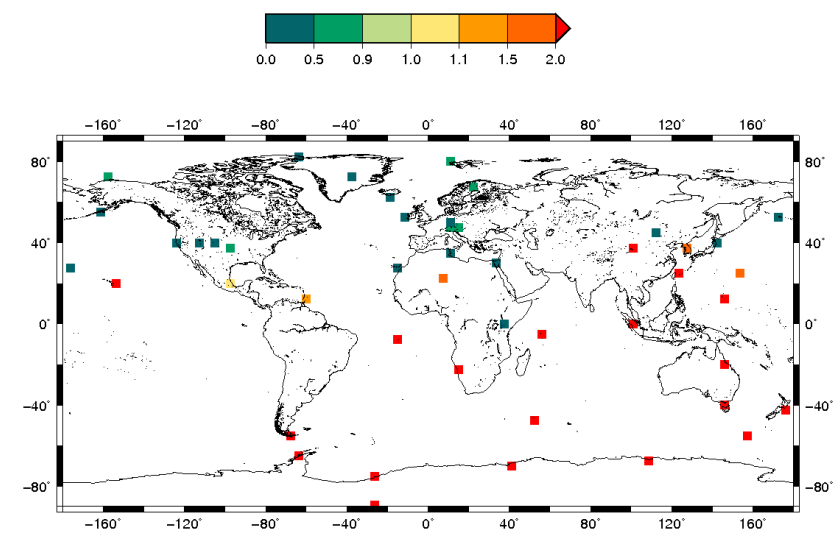

(a) $T A_{1}^{1}$

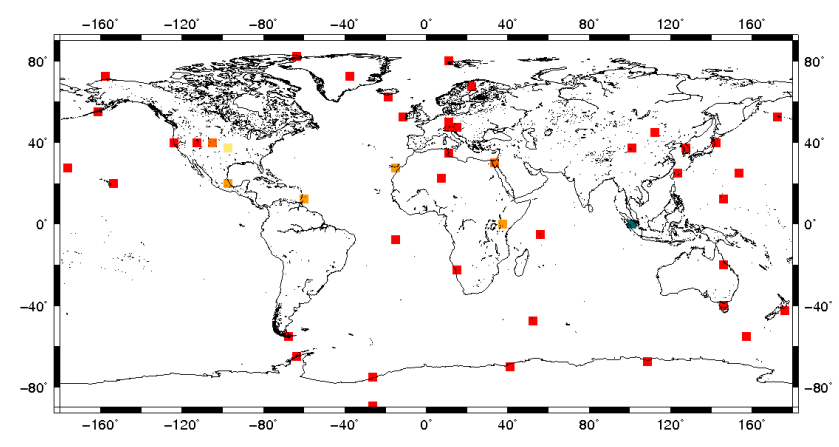

(b) $S C_{1}^{1}$

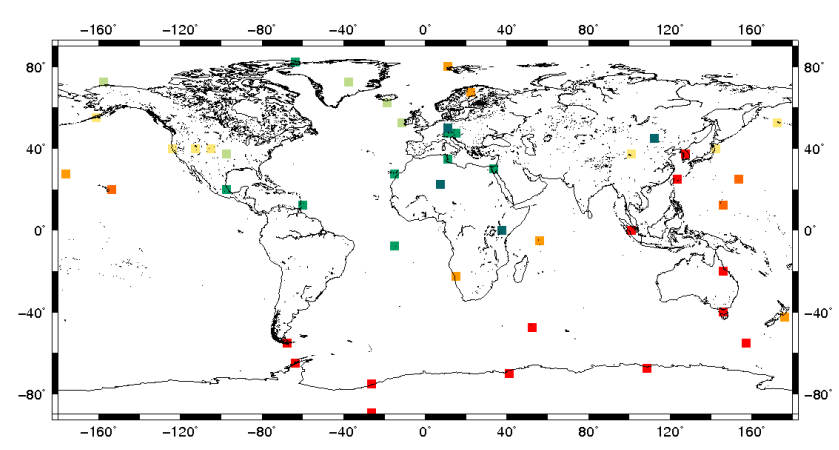

(c) $I A_{1}^{1}$

Fig. 7. Fit at surface sites (unitless) represented as the ratio of the posterior to the prior values of bias (in absolute values) between simulated and observed methane concentrations.

of SCIAMACHY and TANSO-FTS respectively. As shown by Fig. $9 \mathrm{a}, \mathrm{b}$, the linear model is $4.0 \times A_{\mathrm{F}}-34.0 \mathrm{ppb}$ for TANSO-FTS and $13.7 \times A_{\mathrm{F}}-26.6 \mathrm{ppb}$ for SCIAMACHY. $\mathrm{SC}_{1}^{1} \mathrm{C}_{\mathrm{AF}}$ and $\mathrm{TA}_{1}^{1} \mathrm{C}_{\mathrm{AF}}$ are compared to $\mathrm{SC}_{1}^{1}$ and $\mathrm{TA}_{1}^{1}$ from Sect. 4.1 to evaluate the impact of such a correction.

\subsubsection{Global and regional budgets}

At the global scale, as shown by Fig. $3 \mathrm{~b}$ and Table 3, the bias correction decreases both posterior emissions and losses for TANSO-FTS respectively by $1 \%\left(6 \mathrm{Tg} \mathrm{yr}^{-1}\right)$ and $0.6 \%$ $\left(3 \mathrm{Tg} \mathrm{yr}^{-1}\right)$, leading to a decrease of $7 \%$ in the annual growth 


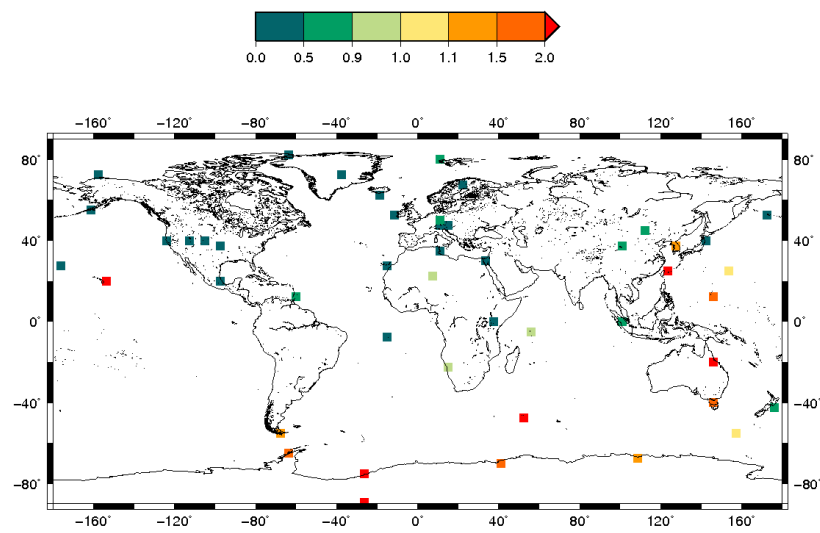

(a) $S U_{1}^{1}$

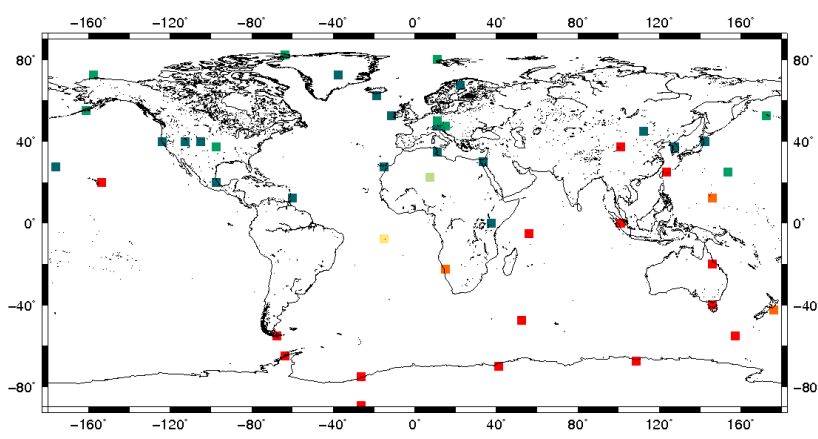

(b) $T A_{1}^{1} C_{A F}$

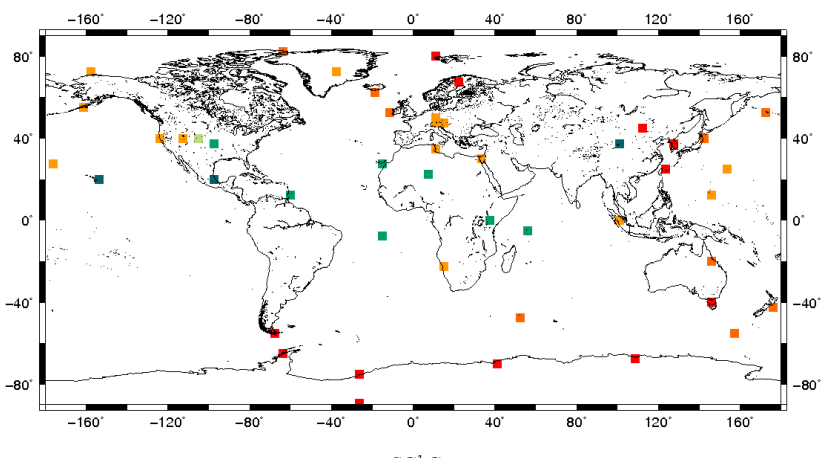

(c) $S C_{1}^{1} C_{A F}$

Fig. 8. Fit at surface sites (unitless) represented as the ratio of the posterior to the prior values of bias (in absolute values) between simulated and observed methane concentrations.

rate (36 $\mathrm{Tg} \mathrm{yr}^{-1}$ instead of $39 \mathrm{Tg} \mathrm{yr}^{-1}$ without correction). For SCIAMACHY, the correction increases both posterior emissions and losses respectively by $0.7 \%\left(4 \mathrm{Tg} \mathrm{yr}^{-1}\right)$ and $0.2 \%\left(2 \mathrm{Tgyr}^{-1}\right)$, leading to an increase of $6 \%$ in the annual growth rate $\left(53 \mathrm{Tg} \mathrm{yr}^{-1}\right.$ instead of $51 \mathrm{Tg} \mathrm{yr}^{-1}$ without correction). The correction induces increments of the same order of magnitude for the two satellites but these do not have the same signs. The bias correction in TANSO-FTS retrievals shows methane emissions, growth rates and fit to surface sites closer to the surface-based inversion ones. For SCIAMACHY, the correction does not improve the agree-

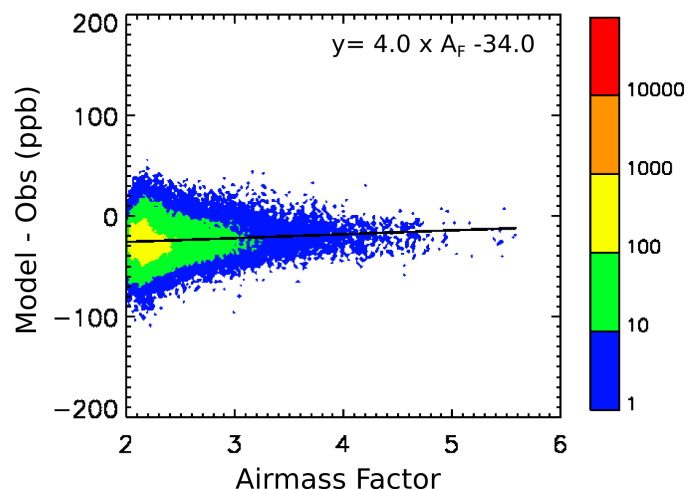

(a)

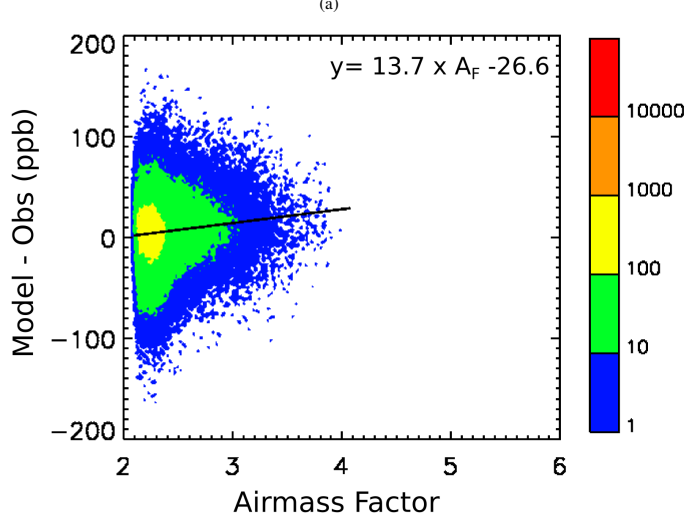

Fig. 9. Linear regression for $S U_{1}^{1}$ posterior state (model) minus TANSO-FTS observations (a) or SCIAMACHY observations (b) as a function of the air mass factor $\left(A_{F}\right)$.

ment between the posterior state and the surface in terms of methane emissions and growth rates even though improves the fit to independent surface sites (see Fig. 8c and Table 3).

At the regional scale, when compared to the non-corrected inversion $\mathrm{TA}_{1}^{1}$, posterior methane emissions of $\mathrm{TA}_{1}^{1} \mathrm{C}_{\mathrm{AF}}$ are slightly increased or decreased, getting closer to the reference inversion for all regions. As shown by Fig. 4c, the emissions are increased especially in mid- and highlatitudes, such as in region East Europe $(+13 \%)$. They are decreased especially in the Tropics, such as in region Indonesia $(-7.6 \%)$. For SCIAMACHY, the correction triggers increases or decreases following the reference increments for almost all regions, with exceptions particularly in regions South American Tropical $(-4 \%)$ and South American Temperate $(+4 \%)$. The correction only infers marginal variations of methane emissions and does not improve the agreement between $\mathrm{SC}_{1}^{1} \mathrm{C}_{\mathrm{AF}}$ and the surface-based inversion at the regional scale. As surface measurements are especially located in mid- and high-latitudes, it makes sense that the largest inconsistencies with the reference concern the Tropics. 
Table 3. Global emissions, chemical losses, growth rates of methane, fit to surface sites described by the absolute mean bias and rms. $\mathrm{XX}_{\gamma}^{\alpha}$ where XX is a two-letter code specific to each observing system (SC for SCIAMACHY, TA for TANSO-FTS, IA for IASI and SU for surface sites); $\alpha$ and $\gamma$ are the multiplicative factors associated with the covariance matrices $\mathbf{B}$ (see Sect. 3.1) and $\mathbf{R}$ (see Sect. 3.3).

\begin{tabular}{lrrrrr}
\hline Name & $\begin{array}{r}\text { Emissions } \\
\mathrm{Tg} \mathrm{yr}^{-1}\end{array}$ & $\begin{array}{r}\text { Loss } \\
\mathrm{Tg} \mathrm{yr}^{-1}\end{array}$ & $\begin{array}{r}\text { Growth rate } \\
\mathrm{Tg} \mathrm{yr}^{-1}\end{array}$ & $\begin{array}{r}\text { Mean bias } \\
\text { ppb }\end{array}$ & $\begin{array}{r}\mathrm{Rms} \\
\mathrm{ppb}\end{array}$ \\
\hline PRIOR & $554 \pm 51$ & $535 \pm 51$ & $19 \pm 50$ & 24.3 & 28.1 \\
$\mathrm{SU}_{1}^{1}$ & $535 \pm 20$ & $518 \pm 51$ & $17 \pm 31$ & 0.8 & 5.5 \\
$\mathrm{TA}_{1}^{1}$ & $576 \pm 30$ & $537 \pm 51$ & $39 \pm 38$ & 4.1 & 15.4 \\
$\mathrm{SC}_{1}^{1}$ & $578 \pm 25$ & $527 \pm 51$ & $51 \pm 36$ & 39.1 & 40.5 \\
$\mathrm{IA}_{1}^{1}$ & $542 \pm 22$ & $533 \pm 51$ & $9 \pm 35$ & 13.0 & 20.0 \\
$\mathrm{TA}_{1}^{1} \mathrm{C}_{\mathrm{AF}}$ & $570 \pm 30$ & $534 \pm 51$ & $36 \pm 23$ & 2.7 & 13.7 \\
$\mathrm{SC}_{1}^{1} \mathrm{C}_{\mathrm{AF}}$ & $582 \pm 25$ & $529 \pm 51$ & $53 \pm 22$ & 23.4 & 26.4 \\
$\mathrm{SU}_{1}^{0.6}$ & $538 \pm 15$ & $519 \pm 30$ & $19 \pm 24$ & 9.1 & 10.3 \\
$\mathrm{TA}_{0.075}^{0.6}$ & $565 \pm 21$ & $537 \pm 30$ & $28 \pm 25$ & 2.2 & 16.1 \\
$\mathrm{SC}_{0.2}^{0.6}$ & $631 \pm 16$ & $549 \pm 30$ & $83 \pm 28$ & 39.7 & 44.3 \\
$\mathrm{IA}_{0.22}^{0.6}$ & $530 \pm 16$ & $530 \pm 30$ & $0 \pm 20$ & 15.5 & 23.6 \\
$\mathrm{TA}_{0.075}^{1.5}$ & $568 \pm 29$ & $541 \pm 71$ & $27 \pm 48$ & 1.9 & 15.2 \\
$\mathrm{IA}_{0.22}^{1.5}$ & $549 \pm 36$ & $536 \pm 71$ & $13 \pm 50$ & 12.4 & 19.2 \\
\hline
\end{tabular}

\subsubsection{Initial conditions}

The initial columns of the two configurations using TANSOFTS observations have the same spatial distribution. However, the bias correction infers larger negative increments in the Northern Hemisphere and weaker positive increments in the Southern Hemisphere. The intial columns of the two configurations of SCIAMACHY are dominated by a strong decrease compared to the prior (see Fig. 6c) with the largest negative variations (around 3\%) located in the Northern Hemisphere. The $\mathrm{CH}_{4}$ initial columns vary by $1.1 \pm 0.6 \%$ without correction $\left(\mathrm{SC}_{1}^{1}\right)$ and by $0.8 \pm 0.5 \%$ with the bias correction $\left(\mathrm{SC}_{1}^{1} \mathrm{C}_{\mathrm{AF}}\right)$. The bias correction seems to make the spatial distribution of the $\mathrm{SC}_{1}^{1} \mathrm{C}_{\mathrm{AF}}$ initial conditions agree more with $\mathrm{TA}_{1}^{1}$ or $\mathrm{TA}_{1}^{1} \mathrm{C}_{\mathrm{AF}}$ initial conditions (Figs. 5a, 6b), which show a positive anomaly in the Tropics of the Southern Hemisphere.

\subsubsection{Fit to surface measurements}

For TANSO-FTS, the mean bias between the model and the surface observations is decreased from $4.1 \mathrm{ppb}$ to $2.7 \mathrm{ppb}$ (see Table 3 ) and the rms is slightly reduced from $15.4 \mathrm{ppb}$ to $13.7 \mathrm{ppb}$ after the bias correction. The bias correction marginally improves the fit to surface sites in the Northern Hemisphere where five more sites show better agreement between surface measurements and the posterior state of the corrected version $\mathrm{TA}_{1}^{1} \mathrm{C}_{\mathrm{AF}}$ (Fig. 8b). For SCIAMACHY, the fit to the surface sites is slightly improved in the mid-latitudes and better in the Tropics (see Figs. 7b and 8c). The bias correction improves the fit for 10 sites located in the two hemispheres while the mean bias is reduced from $39.1 \mathrm{ppb}$ to $23.4 \mathrm{ppb}$ and the rms is reduced from $40.5 \mathrm{ppb}$ to $26.4 \mathrm{ppb}$ but still not better than the prior (mean bias $=24.3 \mathrm{ppb}$ and $\mathrm{rms}=28.1 \mathrm{ppb}$ ).

\subsection{Tuning of error statistics}

\subsubsection{Diagnostics on default configurations}

The results of the diagnostics introduced in Sect. 2.3 and applied to the default configurations $\mathrm{SU}_{1}^{1}, \mathrm{SC}_{1}^{1}, \mathrm{TA}_{1}^{1}$ and $\mathrm{IA}_{1}^{1}$ are presented in Table 4 . They suggest that prior error variances are overestimated by almost 2-fold for the surface $\left(\right.$ ratio $\left._{b}=1.68\right)$ and SCIAMACHY $\left(\right.$ ratio $\left._{b}=1.82\right)$ while they are underestimated by 1.5 for TANSO-FTS $\left(\right.$ ratio $\left._{b}=0.64\right)$ and IASI $\left(\right.$ ratio $\left._{b}=0.69\right)$. The differences among prior error diagnostics for the four observing systems likely stems from the use of a single scaling factor for the whole matrix that may have a more complex structure in reality. Each observing system suggests a scaling factor in this context, based on its own spatial and temporal sensitivity.

The observation errors seem to be fairly well represented in our system for the surface $\left(\right.$ ratio $\left._{o}=0.79\right)$ even though they are overestimated by 13 -fold for TANSO-FTS 


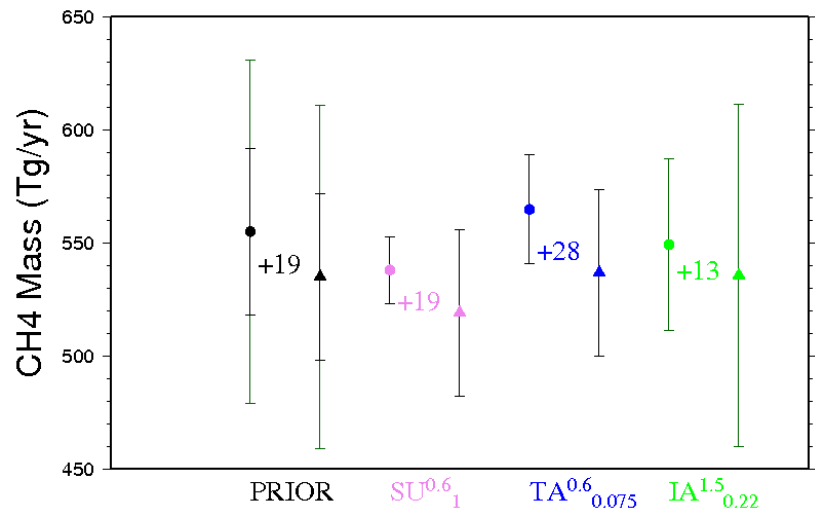

(a)

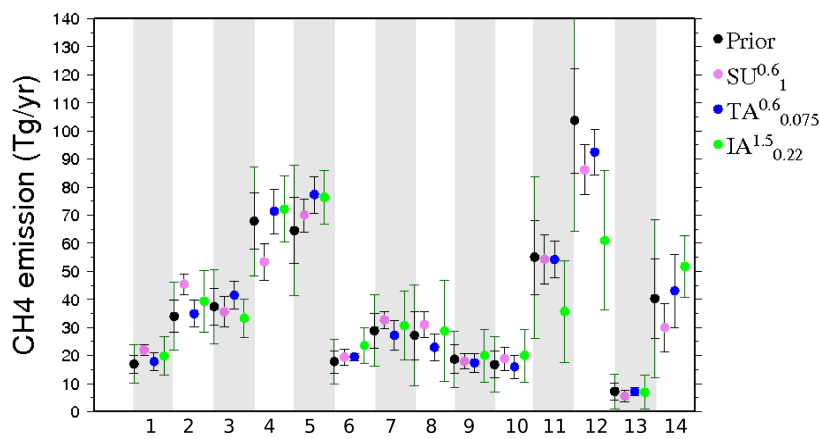

(b)

Fig. 10. Global emissions (circles) and losses (triangles) (a) and regional emissions (b) for the "optimal" configurations $T A_{0.075}^{0.6}$ (blue), $I A_{0.22}^{0.6}$ (green) and $S U_{1}^{0.6}$ (violet). Numbers describe the global growth rates in $\mathrm{Tg} \mathrm{yr}^{-1}$ inferred by the inversions. Error bars represent either the prior uncertainties $(\alpha=0.6$ in black and $\alpha=1.5$ in dark green) or the posterior uncertainties estimated with the Monte Carlo study (see Sect. 2.1).

$\left(\right.$ ratio $\left._{o}=13.69\right)$, by 5-fold for SCIAMACHY $\left(\right.$ ratio $\left._{o}=5.00\right)$ and by 4 -fold for IASI ( atio $\left._{o}=4.41\right)$. The initial value of ratio $_{o}$ for the satellites is related to our use of a diagonal $\mathbf{R}$, with inflated variances qualitatively compensating for missing correlations (see Sect. 2.1). It should be noted that the diagnostics do not account for this numerical artifact.

The full variances are slightly overestimated for the surface (ratio $=1.54$ ) while they are overestimated by 4 -fold for TANSO-FTS and SCIAMACHY (ratio $=4.24$ for $\mathrm{TA}_{1}^{1}$ and ratio $=4.60$ for $\mathrm{SC}_{1}^{1}$ ) and by 2 -fold for IASI (ratio $=2.12$ for $\left.\mathrm{IA}_{1}^{1}\right)$.

From these diagnostics, we perform two tuning experiments series where we tune observation and prior error variances. We evaluate the results based on their agreement with our reference system, i.e. the surface network.
Table 4. Ratios (unitless) of the observation $\left(\right.$ ratio $\left._{o}\right)$, prior ( ratio $_{b}$ ) and full (ratio) variances inferred from the diagnostics presented in Sect. 2.3. These quantities are respectively defined as the ratios between prescribed $\left(\operatorname{var}_{\mathrm{o}}\right.$, $\operatorname{var}_{\mathrm{b}}$ and var $\left.=\operatorname{var}_{\mathrm{o}}+\operatorname{var}_{\mathrm{b}}\right)$ and associated diagnosed ( $\operatorname{diag}_{\mathrm{o}}, \operatorname{diag}_{\mathrm{b}}$ and diag) error variances and represent the goodness of the error statistics in the inversion system. Good statistical consistency is obtained when the ratios are close to 1 .

\begin{tabular}{llll}
\hline NAME & ratio $_{\mathrm{o}}$ & ratio $_{\mathrm{b}}$ & ratio \\
\hline $\mathrm{SU}_{1}^{1}$ & 0.79 & 1.68 & 1.54 \\
$\mathrm{TA}_{1}^{1}$ & 13.69 & 0.64 & 4.24 \\
$\mathrm{SC}_{1}^{1}$ & 5.00 & 1.82 & 4.60 \\
$\mathrm{IA}_{1}^{1}$ & 4.41 & 0.69 & 2.12 \\
$\mathrm{SU}_{1}^{0.6}$ & 0.74 & 0.94 & 0.90 \\
$\mathrm{TA}_{0.075}^{0.6}$ & 1.17 & 0.38 & 0.49 \\
$\mathrm{SC}_{0.2}^{0.6}$ & 1.06 & 0.93 & 1.03 \\
$\mathrm{IA}_{0.22}^{0.6}$ & 1.00 & 0.41 & 0.58 \\
$\mathrm{TA}_{0.075}^{1.5}$ & 1.11 & 0.95 & 0.96 \\
$\mathrm{IA}_{0.22}^{1.5}$ & 1.00 & 1.01 & 1.00 \\
\hline
\end{tabular}

\subsubsection{Tuning experiments 1}

In the first experiment, we select the prior error variance ( $\alpha=0.6=1 / 1.68$ ) suggested by our reference observing system $\left(\mathrm{SU}_{1}^{1}\right)$. It avoids making the prior error matrix vary with the observing system. For the satellites, the observation errors are tuned in order to satisfy Eq. (5). For the surface, the observation error variances are not tuned as they are rather good already $\left(\right.$ ratio $_{o}=0.79$ for $\left.\mathrm{SU}_{1}^{1}\right)$. This tuning improves all diagnostics for the surface $\left(\right.$ ratio $_{o}=0.74$, ratio $_{b}=0.94$ and ratio $=0.90$ for $\mathrm{SU}_{1}^{0.6}$ see Table 4) and SCIAMACHY $\left(\right.$ ratio $_{o}=1.06$, ratio $_{b}=0.93$ and ratio $=1.03$ for $\left.\mathrm{SC}_{0.2}^{0.6}\right)$ but does not improve the agreement with the reference in terms of mole fractions (see Table 3). For the surface, the fit to assimilated surface sites is degraded. This result is expected as decreasing prior errors limits the possibility of the inversion to deviate from the prior to better fit the assimilated observations. For SCIAMACHY, there is no real improvement of the fit to surface sites after inversion in terms of mean bias (39.7 ppb) and rms (44.3 ppb) when compared to the prior statistics of the bias. This suggests that the observation error variances of SCIAMACHY have a more complex structure than the one tuned here. Otherwise, the observation error diagnostics for TANSO-FTS (ratio ${ }_{o}=1.17$ for $\mathrm{TA}_{0.075}^{0.6}$ ) and IASI ( ratio $_{o}=1.00$ for $\mathrm{IA}_{0.22}^{0.6}$ ) are both improved while the prior error diagnostics are degraded for both satellite instruments $\left(\right.$ ratio $_{b}=0.38$ for $\mathrm{TA}_{0.075}^{0.6}$ and ratio $_{b}=0.41$ for $\mathrm{IA}_{0.22}^{0.6}$ ), confirming the fact that the prior error configuration satisfying for the surface does not fit TANSO-FTS and IASI. 
However, the agreement with independent surface sites is improved in terms of mean bias $(2.2 \mathrm{ppb})$ for TANSO-FTS only (the rms is stable at $16.1 \mathrm{ppb}$ ) and is degraded for IASI ( mean bias $=15.5 \mathrm{ppb}$ and $\mathrm{rms}=23.6 \mathrm{ppb}$ ).

\subsubsection{Tuning experiments 2}

In the second experiment, we tune both prior and observation error variances following the diagnostics specific to TANSO-FTS and IASI. As suggested by the diagnostics applied on the default configurations, we set $\alpha=1.5$ for prior errors $\left(\right.$ ratio $_{b}=0.64$ for TANSO-FTS and ratio $_{b}=0.69$ for IASI) and the observation errors are independently tuned $\left(\right.$ ratio $_{o}=13.69$ for TANSO-FTS and ratio $_{o}=4.41$ for IASI). The results of the diagnostics for the configurations $\mathrm{TA}_{0.075}^{1.5}$ and $\mathrm{IA}_{0.22}^{1.5}$ are presented in Table 4 . They suggest that all error variances are fairly well prescribed in our system now $\left(\right.$ ratio $=0.96$ for $\mathrm{TA}_{0.075}^{1.5}$ and ratio $=1.00$ for $\left.\mathrm{IA}_{0.22}^{1.5}\right)$. The fit to surface sites are improved by this tuning in terms of mean bias and rms for both instruments when compared to the default configurations (i.e. when $\alpha=\gamma=1$; see Table 3). However, for TANSO-FTS, the mean bias and rms are similar to the ones obtained by the first tuning experiment with prior error diagnostics degraded (i.e. configuration $\mathrm{TA}_{0.075}^{0.6}$ ), meaning that prior error variances have a minor effect on the quality of the inverted fluxes for this instrument. This is not the case for IASI, for which the prior error configuration has a larger impact on the inverted fluxes. When compared to the first experiment (i.e. $\mathrm{IA}_{0.22}^{0.6}$ ), the growth rate obtained for IASI is increased by $13 \mathrm{Tg} \mathrm{yr}^{-1}$, better agreeing with the surface-based inversions while the fit to surface sites is also improved (mean bias $=12.4 \mathrm{ppb}$ and $\mathrm{rms}=19.2 \mathrm{ppb}$ ).

\section{Discussion}

The two satellite instruments observing in the SWIR domain, TANSO-FTS and SCIAMACHY, infer larger emissions than the other two observing systems, respectively by $+41 \mathrm{Tg} \mathrm{yr}^{-1}$ and $+43 \mathrm{Tg} \mathrm{yr}^{-1}$ for the default configurations (i.e. with $\alpha=\gamma=1$ ), when compared to the surface global budget of $535 \mathrm{Tg} \mathrm{yr}^{-1}$. This overestimation can be partly explained by a bias identified as a function of the air mass factor in the satellite products, respectively of $4.0 \times A_{\mathrm{F}}-34.0 \mathrm{ppb}$ and $13.7 \times A_{\mathrm{F}}-26.6 \mathrm{ppb}$. Correcting this bias improves the agreement between TANSO-FTS and the surface at global and regional scales and the fit to surface measurements as well. However, given the modesty of the bias and the uncertainty of the linear regression, its need is not obvious. For SCIAMACHY, the bias correction has a slight impact on the inverted methane emissions and does not improve the agreement with the surface at global and regional scales. It has a larger impact on the fit to surface measurements in terms of mole fractions, which is well improved when compared to the default configuration. However, for the bias- corrected configuration $\mathrm{SC}_{1}^{1} \mathrm{C}_{\mathrm{AF}}$, the mean bias $(23.4 \mathrm{ppb})$ and rms $(26.4 \mathrm{ppb})$ are slightly improved by this inversion, when compared to the prior ones, but remain large. Such a correction is needed for SCIAMACHY, albeit not sufficient to reconcile the posterior state with the reference.

When comparing configuration $\mathrm{TA}_{0.075}^{1.5}$ with the other test configuration (e.g. $\mathrm{TA}_{0.075}^{0.6}$ ), the fit to surface sites is similar since mean bias and rms are very close. The two sets of tuning experiments indicate that the information inferred from TANSO-FTS is robust in our system in terms of mole fractions and growth rates. IASI seems to be more sensitive to prior error assignment as methane emissions vary by $19 \mathrm{Tg} \mathrm{yr}^{-1}$ and growth rates by $13 \mathrm{Tg} \mathrm{yr}^{-1}$ among all sensitivity tests. Indeed, with a tuning specific to this satellite instrument, one gets a stable agreement with independent surface sites. Based on the fit to surface measurements, the inversions $\mathrm{TA}_{0.075}^{0.6}$ and $\mathrm{IA}_{0.22}^{1.5}$ are taken as optimal configurations obtained from the tuning procedure. The corresponding emission and loss budgets are summarized in Fig. 10. For all SCIAMACHY sensitivity tests, the mean bias and rms are worse than the prior ones, meaning that the inversion process does not improve the agreement with the surface measurements for this satellite. It seems that SCIAMACHY cannot agree with the reference by simply adjusting mean prior and observation error variances. This points to a complicated structure of the retrieval errors, at least for the period studied, possibly linked to the progressive degradation of the instrument. Direct conclusions regarding SCIAMACHY for earlier time periods cannot be drawn from our study, which focuses on years 2009-2010, the only overlap period between SCIAMACHY and GOSAT.

For all observing systems, the largest emissions are located in region South American Tropical and may be explained by methane emissions from wetlands and from biomass burning further to the severe drought in Amazonia in 2010. Large emissions are inferred as well in region South Africa, which are probably also caused by biomass burning. IASI differs from the other two observing systems in some regions. An overestimation of the emissions (when compared to the reference) in Indonesia compensates an underestimation of the emissions in Asia, suggesting a misattribution of the emissions in these regions likely due to the large footprint of the mid-to-upper tropospheric column combined with a lack of retrievals during the monsoon period, i.e. between June and September. Another underestimation of the emissions in region South American Tropical is seen as well, also due to a lack of IASI retrievals over this region between November 2009 and March 2010. This does not allow inferring the high emissions found by TANSO-FTS and the surface data during the drought of 2010.

The three observing systems (TANSO-FTS, IASI and the surface sites) still show good consistency in terms of emissions, meaning we can trust the main information retrieved from them. However, in the Southern Hemisphere 
the fit is not improved for the sites optimized during the surface-based inversions. Interestingly, we found a similar problem when inverting $\mathrm{CO}$ emissions from the Measurements Of Pollution In The Troposphere (MOPITT) on board NASA's Terra satellite (Fortems-Cheiney et al., 2011). These two results may be partly explained by the too small exchange time of this version of the LMDz transport model from the Northern Hemisphere to the Southern Hemisphere (Patra et al., 2011), which likely induces an artificial increase of the sources inferred in the North and an increase of the loss in the South to match the surface observations.

\section{Conclusion}

Using objective tuning methods for the error statistics, we show that one can achieve improved consistency between $\mathrm{CH}_{4}$ emission and loss inferred from different observing systems. An exception is SCIAMACHY, which seems to be particularly difficult to exploit over the period 2009-2010. The tuned covariance matrix is more optimistic about the quality of the prior fluxes than our initial estimates when assimilating the global TANSO-FTS or the global surface network, whereas it is more conservative when assimilating the tropical IASI data. The observation error, initially set at around $8 \%$ for TANSO-FTS and around $3 \%$ for IASI, is reduced by 13-fold for TANSO-FTS and by 4-fold for IASI. The global TANSO-FTS, IASI and surface data budgets from the improved configurations are respectively $565 \pm 21 \mathrm{Tg} \mathrm{gr}^{-1}$, $549 \pm 36 \mathrm{Tg} \mathrm{yr}^{-1}$ and $538 \pm 15 \mathrm{Tg} \mathrm{yr}^{-1}$ for the period August 2009-July 2010. To assess the current methane budget with TANSO-FTS, IASI and the surface sites, one can keep one or two of these observing systems out of the inversion for independent evaluation, as we propose here. Alternatively, one can combine them together to better reduce uncertainties in the methane cycle, provided the tuning of the prior error is regionalized.

Acknowledgements. The first author is funded by CNES and CEA. This work was performed using HPC resources from DSM-CCRT and [CCRT/CINES/IDRIS] under the allocation 2012-t2012012201 made by GENCI (Grand Equipement National de Calcul Intensif). We also thank the computing support team of the LSCE led by F. Marabelle. We aknowledge the contributors to the World Data Center for Greenhouse Gases for providing their data of methane and methyl-chloroform atmospheric mole fractions. The authors thank in particular S. Piacentino (ENEA), T. Kawasato (JMA) and S. Nichol (NIWA). NOAA authors receive partial funding for their measurements and research from the Atmospheric Chemistry, Carbon Cycle, and Climate (AC4) Program.

Edited by: A. Pozzer

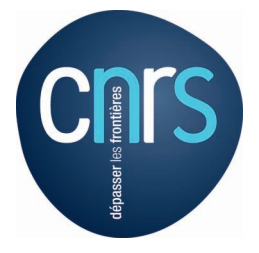

The publication of this article is financed by CNRS-INSU.

\section{References}

Artuso, F., Chamard, P., Piacentino, S., Di Sarra, A., Meloni, D., Monteleone, F., Sferlazzo, D. M., and Thiery, F.: Atmospheric methane in the Mediterranean: analysis of measurements at the island of Lampedusa during 1995-2005, Atmos. Environ., 41, 3877-3888, doi:10.1016/j.atmosenv.2007.01.024, 2007.

Bergamaschi, P., Frankenberg, C., Meirink, J. F., Krol, M., Villani, M. G., Houweling, S., Dentener, F., Dlugokencky, E. J., Miller, J. B., Gatti, L. V., Engel, A., and Levin, I.: Inverse modeling of global and regional $\mathrm{CH} 4$ emissions using SCIAMACHY satellite retrievals, J. Geophys. Res. Atmos., 114, D22301, doi:10.1029/2009JD012287, 2009.

Bergamaschi, P., Krol, M., Meirink, J. F., Dentener, F., Segers, A., van Aardenne, J., Monni, S., Vermeulen, A. T., Schmidt, M., and Ramonet, M.: Inverse modeling of European $\mathrm{CH}_{4}$ emissions 2001-2006, J. Geophys. Res. Atmos., 115, D22309, doi:10.1029/2010JD014180, 2010.

Bocquet, M., Wu, L., and Chevallier, F.: Bayesian design of control space for optimal assimilation of observations. Part I: Consistent multiscale formalism, Q. J. Roy. Meteorol. Soc., 137, 13401356, doi:10.1002/qj.837, 2011.

Bousquet, P., Hauglustaine, D. A., Peylin, P., Carouge, C., and Ciais, P.: Two decades of $\mathrm{OH}$ variability as inferred by an inversion of atmospheric transport and chemistry of methyl chloroform, Atmos. Chem. Phys., 5, 2635-2656, doi:10.5194/acp-52635-2005, 2005.

Bousquet, P., Ciais, P., Miller, J. B., Dlugokencky, E. J., Hauglustaine, D. A., Prigent, C., Werf, G. R. V. d., Peylin, P., Brunke, E.-G., Carouge, C., Langenfelds, R. L., Lathière, J., Papa, F., Ramonet, M., Schmidt, M., Steele, L. P., Tyler, S. C., and White, J.: Contribution of anthropogenic and natural sources to atmospheric methane variability, Nature, 443, 439-443, doi:10.1038/nature05132, 2006.

Bousquet, P., Ringeval, B., Pison, I., Dlugokencky, E. J., Brunke, E.G., Carouge, C., Chevallier, F., Fortems-Cheiney, A., Frankenberg, C., Hauglustaine, D. A., Krummel, P. B., Langenfelds, R. L., Ramonet, M., Schmidt, M., Steele, L. P., Szopa, S., Yver, C., Viovy, N., and Ciais, P.: Source attribution of the changes in atmospheric methane for 2006-2008, Atmos. Chem. Phys., 11, 3689-3700, doi:10.5194/acp-11-3689-2011, 2011.

Chapnik, B., Desroziers, G., Rabier, F., and Talagrand, O.: Diagnosis and tuning of observational error in a quasi-operational data assimilation setting, Q. J. Roy. Meteorol. Soc., 132, 543-565, doi:10.1256/qj.04.102, 2006.

Chen, Y.-H. and Prinn, R. G.: Estimation of atmospheric methane emissions between 1996 and 2001 using a three-dimensional global chemical transport model, J. Geophys. Res. Atmos., 111, D10307, doi:10.1029/2005JD006058, 2006.

Chevallier, F.: Impact of correlated observation errors on inverted CO2 surface fluxes from OCO measurements, Geophys. Res. Lett., 34, L24804, doi:10.1029/2007GL030463, 2007. 
Chevallier, F., Fisher, M., Peylin, P., Serrar, S., Bousquet, P., Bréon, F. M., Chédin, A., and Ciais, P.: Inferring $\mathrm{CO} 2$ sources and sinks from satellite observations: Method and application to TOVS data, J. Geophys. Res., 110, D24309, doi:10.1029/2005JD006390, 2005.

Chevallier, F., Bréon, F. M., and Rayner, P. J.: Contribution of the Orbiting Carbon Observatory to the estimation of $\mathrm{CO} 2$ sources and sinks: Theoretical study in a variational data assimilation framework, J. Geophys. Res., 112, D09307, doi:10.1029/2006JD007375, 2007.

Chevallier, F., Feng, L., Bösch, H., Palmer, P. I., and Rayner, P. J.: On the impact of transport model errors for the estimation of $\mathrm{CO}_{2}$ surface fluxes from GOSAT observations, Geophys. Res. Lett., 37, L21803, doi:10.1029/2010GL044652, 2010.

Crevoisier, C., Nobileau, D., Fiore, A. M., Armante, R., Chédin, A., and Scott, N. A.: Tropospheric methane in the tropics - first year from IASI hyperspectral infrared observations, Atmos. Chem. Phys., 9, 6337-6350, doi:10.5194/acp-9-6337-2009, 2009.

Crevoisier, C., Nobileau, D., Armante, R., Crépeau, L., Machida, T., Sawa, Y., Matsueda, H., Schuck, T., Thonat, T., Pernin, J., Scott, N. A., and Chédin, A.: The 2007-2011 evolution of tropical methane in the mid-troposphere as seen from space by MetOpA/IASI, Atmos. Chem. Phys., 13, 4279-4289, doi:10.5194/acp13-4279-2013, 2013.

Desroziers, G., Berre, L., Chapnik, B., and Poli, P.: Diagnosis of observation, background and analysis-error statistics in observation space, Q. J. Roy. Meteorol. Soc., 131, 3385-3396, doi:10.1256/qj.05.108, 2006.

Dlugokencky, E. J., Steele, L. P., Lang, P. M., and Masarie, K. A.: The growth rate and distribution of atmospheric methane, J. Geophys. Res. Atmos., 99, 17021-17043, doi:10.1029/94JD01245, 1994.

Dlugokencky, E. J., Bruhwiler, L., White, J. W. C., Emmons, L. K., Novelli, P. C., Montzka, S. A., Masarie, K. A., Lang, P. M., Crotwell, A. M., Miller, J. B., and Gatti, L. V.: Observational constraints on recent increases in the atmospheric $\mathrm{CH} 4$ burden, Geophys. Res. Lett., 36, L18803, doi:10.1029/2009GL039780, 2009.

Forster, P.: Changes in Atmospheric Constituents and in Radiative Forcing, Cambridge University Press, United Kingdom and New York, NY, USA, 129-234, 2007.

Fortems-Cheiney, A., Chevallier, F., Pison, I., Bousquet, P., Szopa, S., Deeter, M. N., and Clerbaux, C.: Ten years of $\mathrm{CO}$ emissions as seen from Measurements of Pollution in the Troposphere (MOPITT), J. Geophys. Res., 116, D05304, doi:10.1029/2010JD014416, 2011.

Francey, R. J., Steele, L. P., Langenfelds, R. L., and Pak, B. C.: High precision long-term monitoring of radiatively active and related trace gases at surface sites and from aircraft in the Southern Hemisphere atmosphere, J. Atmos. Sci., 56, 279-285, doi:10.1175/1520-0469(1999)056<0279:HPLTMO>2.0.CO;2, 1999.

Frankenberg, C., Meirink, J. F., Bergamaschi, P., Goede, A. P. H., Heimann, M., Körner, S., Platt, U., Weele, M. v., and Wagner, T.: Satellite chartography of atmospheric methane from SCIAMACHY on board ENVISAT: Analysis of the years 2003 and 2004, J. Geophys. Res., 111, D07303, doi:10.1029/2005JD006235, 2006.
Gilbert, J. C. and Lemaréchal, C.: Some numerical experiments with variable-storage quasi-Newton algorithms, Mathematical programming, 45, 407-435, doi:10.1007/BF01589113, 1989.

GLOBALVIEW-CH4: Cooperative Atmospheric Data Integration Project - Methane, CD-ROM, NOAA ESRL, Boulder, Colorado, 2009.

Gurney, K. R., Law, R. M., Denning, A. S., Rayner, P. J., Baker, D., Bousquet, P., Bruhwiler, L., Chen, Y.-H., Ciais, P., and Fan, S.: Towards robust regional estimates of $\mathrm{CO} 2$ sources and sinks using atmospheric transport models, Nature, 415, 626-630, doi:10.1038/415626a, 2002.

Hauglustaine, D., Hourdin, F., Jourdain, L., Filiberti, M., Walters, S., Lamarque, J., and Holland, E.: Interactive chemistry in the Laboratoire de Météorologie Dynamique general circulation model: Description and background tropospheric chemistry evaluation, J. Geophys. Res., 109, D04314, doi:10.1029/2003JD003957, 2004.

Hourdin, F., Musat, I., Bony, S., Braconnot, P., Codron, F., Dufresne, J.-L., Fairhead, L., Filiberti, M.-A., Friedlingstein, P., and Grandpeix, J.-Y.: The LMDZ4 general circulation model: climate performance and sensitivity to parametrized physics with emphasis on tropical convection, Clim. Dynam., 27, 787-813, doi:10.1007/s00382-006-0158-0, 2006.

Houweling, S., Kaminski, T., Dentener, F., Lelieveld, J., and Heimann, M.: Inverse modeling of methane sources and sinks using the adjoint of a global transport model, J. Geophys. Res., 104, 26137-26160, doi:10.1029/1999JD900428, 1999.

Kaminski, T., Rayner, P. J., Heimann, M., and Enting, I. G.: On aggregation errors in atmospheric transport inversions, J. Geophys. Res. Atmos., 106, 4703-4715, doi:10.1029/2000JD900581, 2001.

Kaplan, J. O.: Wetlands at the Last Glacial Maximum: Distribution and methane emissions, Geophys. Res. Lett., 29, 3-1-3-4, doi:10.1029/2001GL013366, 2002.

Kirschke, S., Bousquet, P., Ciais, P., Saunois, M., Canadell, J. G., Dlugokencky, E. J., Bergamaschi, P., Bergmann, D., Blake, D. R., and Bruhwiler, L.: Three decades of global methane sources and sinks, Nature Geosci., 6, 813-823, doi:10.1038/ngeo1955, 2013.

Lambert, G. and Schmidt, S.: Reevaluation of the oceanic flux of methane: Uncertainties and long term variations, Chemosphere, 26, 579-589, doi:10.1016/0045-6535(93)90443-9, 1993.

Lowe, D. C., Brenninkmeijer, C. A. M., Tyler, S. C., and Dlugkencky, E. J.: Determination of the isotopic composition of atmospheric methane and its application in the Antarctic, J. Geophys. Res. Atmos., 96, 15455-15467, doi:10.1029/91JD01119, 1991.

Matsueda, H., Sawa, Y., Wada, A., Inoue, H. Y., Suda, K., Hirano, Y., Tsuboi, K., and Nishioka, S.: Methane standard gases for atmospheric measurements at the MRI and JMA and intercomparison experiments, Papers Meteorol. Geophys., 54, 91-113, doi:10.2467/mripapers.54.91, 2004.

Meirink, J. F., Bergamaschi, P., and Krol, M. C.: Fourdimensional variational data assimilation for inverse modelling of atmospheric methane emissions: method and comparison with synthesis inversion, Atmos. Chem. Phys., 8, 6341-6353, doi:10.5194/acp-8-6341-2008, 2008.

Montzka, S. A., Spivakovsky, C. M., Butler, J. H., Elkins, J. W., Lock, L. T., and Mondeel, D. J.: New observational constraints 
for atmospheric hydroxyl on global and hemispheric scales, Science, 288, 500-503, doi:10.1126/science.288.5465.500, 2000.

Montzka, S. A., Krol, M., Dlugokencky, E., Hall, B., Jöckel, P., and Lelieveld, J.: Small interannual variability of global atmospheric hydroxyl, Science, 331, 67-69, doi:10.1126/science.1197640, 2011.

Olivier, J. G. J. and Berdowski, J. J. M.: Global emission sources and sinks, 2001.

Parker, R., Boesch, H., Cogan, A., Fraser, A., Feng, L., Palmer, P. I., Messerschmidt, J., Deutscher, N., Griffith, D. W. T., Notholt, J., Wennberg, P. O., and Wunch, D.: Methane observations from the Greenhouse Gases Observing SATellite: Comparison to groundbased TCCON data and model calculations, Geophys. Res. Lett., 38, L15807, doi:10.1029/2011GL047871, 2011.

Patra, P. K., Houweling, S., Krol, M., Bousquet, P., Belikov, D., Bergmann, D., Bian, H., Cameron-Smith, P., Chipperfield, M. P., and Corbin, K.: TransCom model simulations of $\mathrm{CH} 4$ and related species: linking transport, surface flux and chemical loss with $\mathrm{CH} 4$ variability in the troposphere and lower stratosphere, Atmos. Chem. Phys., 11, 12813-12837, doi:10.5194/acp-1112813-2011, 2011.

Pison, I., Bousquet, P., Chevallier, F., Szopa, S., and Hauglustaine, D.: Multi-species inversion of $\mathrm{CH}_{4}, \mathrm{CO}$ and $\mathrm{H}_{2}$ emissions from surface measurements, Atmos. Chem. Phys., 9, 5281-5297, doi:10.5194/acp-9-5281-2009, 2009.

Prinn, R. G., Huang, J., Weiss, R. F., Cunnold, D. M., Fraser, P. J., Simmonds, P. G., McCulloch, A., Harth, C., Reimann, S., Salameh, P., O’Doherty, S., Wang, R. H. J., Porter, L. W., Miller, B. R., and Krummel, P. B.: Evidence for variability of atmospheric hydroxyl radicals over the past quarter century, Geophys. Res. Lett., 32, L07809, doi:10.1029/2004GL022228, 2005.
Ridgwell, A. J., Marshall, S. J., and Gregson, K.: Consumption of atmospheric methane by soils: A process-based model, Global Biogeochem. Cy., 13, 59-70, doi:10.1029/1998GB900004, 1999.

Rigby, M., Prinn, R. G., Fraser, P. J., Simmonds, P. G., Langenfelds, R. L., Huang, J., Cunnold, D. M., Steele, L. P., Krummel, P. B., Weiss, R. F., O’Doherty, S., Salameh, P. K., Wang, H. J., Harth, C. M., Mühle, J., and Porter, L. W.: Renewed growth of atmospheric methane, Geophys. Res. Lett., 35, L22805, doi:10.1029/2008GL036037, 2008.

Sanderson, M. G.: Biomass of termites and their emissions of methane and carbon dioxide: A global database, Global Biogeochem. Cy., 10, 543-557, doi:10.1029/96GB01893, 1996.

Spahni, R., Wania, R., Neef, L., van Weele, M., Pison, I., Bousquet, P., Frankenberg, C., Foster, P. N., Joos, F., Prentice, I. C., and van Velthoven, P.: Constraining global methane emissions and uptake by ecosystems, Biogeosciences, 8, 1643-1665, doi:10.5194/bg8-1643-2011, 2011.

van der Werf, G., Randerson, J. T., Giglio, L., Collatz, G. J., Mu, M., Kasibhatla, P. S., Morton, D. C., DeFries, R. S., Jin, Y. v., and Leeuwen, T. v.: Global fire emissions and the contribution of deforestation, savanna, forest, agricultural, and peat fires (19972009), Atmos. Chem. Phys., 10, 11707-11735, doi:10.5194/acp10-11707-2010, 2010. 